\title{
Measuring customer satisfaction on the Internet
}

\author{
Citation for published version (APA):
}

Walczuch, R. M., \& Hofmaier, K. (2000). Measuring customer satisfaction on the Internet. METEOR, Maastricht University School of Business and Economics. METEOR Research Memorandum No. 051 https://doi.org/10.26481/umamet.2000051

Document status and date:

Published: 01/01/2000

DOI:

10.26481/umamet.2000051

Document Version:

Publisher's PDF, also known as Version of record

\section{Please check the document version of this publication:}

- A submitted manuscript is the version of the article upon submission and before peer-review. There can be important differences between the submitted version and the official published version of record.

People interested in the research are advised to contact the author for the final version of the publication, or visit the DOI to the publisher's website.

- The final author version and the galley proof are versions of the publication after peer review.

- The final published version features the final layout of the paper including the volume, issue and page numbers.

Link to publication

\footnotetext{
General rights rights.

- You may freely distribute the URL identifying the publication in the public portal. please follow below link for the End User Agreement:

www.umlib.nl/taverne-license

Take down policy

If you believe that this document breaches copyright please contact us at:

repository@maastrichtuniversity.nl

providing details and we will investigate your claim.
}

Copyright and moral rights for the publications made accessible in the public portal are retained by the authors and/or other copyright owners and it is a condition of accessing publications that users recognise and abide by the legal requirements associated with these

- Users may download and print one copy of any publication from the public portal for the purpose of private study or research.

- You may not further distribute the material or use it for any profit-making activity or commercial gain

If the publication is distributed under the terms of Article $25 \mathrm{fa}$ of the Dutch Copyright Act, indicated by the "Taverne" license above, 


\title{
Measuring Customer Satisfaction on the Internet
}

\author{
Rita M. Walczuch and Katja Hofmaier
}

MARC Working Paper MARC-WP/3/2000-13

Also published in the proceedings of RSEEM 1999, 17. - 19.9.1999, Muenster, Germany.

\begin{abstract}
Based on the Expectancy Disconfirmation Model as the underlying construct, methods to measure customer satisfaction with products and the steps to be undertaken in the research process are investigated. The measurement of Derived Satisfaction using (dis)confirmation was identified to be the appropriate approach to CS measurement. Prior research has also shown that during the research process, several points specific to CS measurements need to be accounted for.

The Internet services currently used by marketing and social researchers include E-mail, mailinglists, newsgroups, Internet Chat, the World Wide Web $(W W W)$ and Virtual Worlds. Virtual Worlds, being most advantageous for observational studies, are not useful for customer satisfaction research. Virtual Communities, in turn, have some promising characteristics for future use. Internet research methods based on these services include E-mail surveys and $W W W$-surveys. Common advantages of E-mail-and $W W W$-surveys include administrative and response speed, cost savings and global reach of respondents. Their greatest common disadvantage is the non-representativeness of the respondents for the larger population as well as their selfselection. Unless access is restricted to a known population, probability sampling is impossible when using the World Wide Web.

Based on these insights, the Internet was found to be an advantageous medium for customer satisfaction studies only if specific conditions are met. Companies need to investigate on a case-by-case basis if the online measurement of customer satisfaction is possible in their specific situation. The recommendations were summarized in a decision-making framework.

The results of a survey among market research agencies show that practitioners are to a large extent aware of the limitations within which the Internet can be used for customer satisfaction surveys. However, especially $W W W$-surveys sometimes are conducted in a way that does not lead to representative results.
\end{abstract}




\section{Introduction}

The importance of customer satisfaction has gained considerable attention in the marketing literature. "As the cornerstone of the marketing concept, customer satisfaction has been embraced by practitioners and academics alike as the highest-order goal of the company" (Peterson \& Wilson, 1992, p 61). With increasing global competition, accelerating customer choice opportunities and demands, customer satisfaction has become a vital goal for the survival of the company. Individual countries as well as the European Union have recognized this importance and started to develop their own customer satisfaction indices in order to provide their companies with a standard benchmark within their industry or country (Bruhn, 1998).

Since its opening to private and commercial use in 1995, the Internet has been growing tremendously (Agrawal, 1998). Because of this tremendous growth, the new medium has also gained the interest of (marketing) researchers. Coomber summarizes that "the existence of the Internet and the World Wide Web (WWW) clearly provides new horizons for the researcher. A potentially vast population of all kinds of individuals and groups may be more easily reached than ever before, across geographical borders and even continents" (Coomber, 1997).

Although Internet marketing research is gaining popularity and studies concerning this subject are finally emerging on a larger scale, no specific investigations of customer satisfaction measurements on the Internet could be found. This paper will therefore investigate how customer satisfaction can be realized on the Internet. A few studies concerning WWW-Surveys and E-mail surveys have been investigating market research on the Internet from various viewpoints and have produced some scattered knowledge. Schillewaert et al. ask that "future studies should be aimed at developing a comprehensive framework for describing when to use and when not to use the various sampling methods for WWW surveys" (Schillewaert, Langerak, \& Duhamle, 1998, p 320). The aim of this paper is to firstly accumulate the findings of previous related research. Based on the insights from these studies some recommendations are developed, which are then combined in a decisionmaking framework. The recommendations given can furthermore be used as reference points for refining future studies. The paper also reports the results of a survey among marketing research companies, which investigates how customer satisfaction research on the Internet is performed in practice and identifies gaps between theory and practice. Because of the difference in the satisfaction formation between products and services, customer satisfaction with products is the focus of this paper.

\section{The Expectancy Disconfirmation Model}

The construct of customer satisfaction (CS) has been researched extensively during the past decades. However, as of today, no generally accepted model has emerged (Berger \& Mens van, 1997; Johnson, Anderson, \& Fornell, 1995; Kaapke \& Hudet, 1998). In this paper, the dominant model underlying customer satisfaction research, the Expectancy Disconfirmation Model has been chosen.

Richard Oliver led customer satisfaction research with the Expectancy Disconfirmation Model. This model has consistently been validated in empirical research (Engel, Blackwell, \& Miniard, 1995; Peter \& Olson, 1996) as well as build upon by various scholars (e.g. (Gupta \& Stewart, 1996; Halstead, Hartmann, \& Schmidt, 1994; Oliver \& De Sarbo, 1988; Patterson, Johnson, \& Spreng, 1997; Spreng, McKenzie, \& Olshavsky, 1996; Tse \& Wilton, 1988)).

According to the Expectancy Disconfirmation Model, a customer's satisfaction has three antecedents: Prepurchase expectations, perceived product performance and confirmation or disconfirmation of these expectations. While the role of affect has not yet been resolved clearly, there is consensus over the existence of an emotional reaction to the intensity of satisfaction experienced (Müller, 1998). As of today, this model has 
been dominant in theoretical CS research (Berger \& Mens van, 1997; Boulding, Kalra, Staelin, \& Zeithaml, 1993; Engel et al., 1995; Gupta \& Stewart, 1996; Müller, 1998).

Expectations have been defined differently by various researchers. Wilton et al. (Tse \& Wilton, 1988), treat expectations as the likelihood of an event as well as an evaluation of its goodness or badness. Müller (Müller, 1998) summarizes the following expectation concepts, which can be found in the CS-literature: Expectations as ideal product performance expectations, minimal expectations, and product-specific norms. According to the current literature (Berger \& Mens van, 1997; Klingebiel, 1998; Müller, 1998), expected product performance defined as a product's most likely performance ('predictive expectations') is the most common presumption used in customer satisfaction research. Engel et al. support this statement with the motivation that "this is the logical outcome of the pre-purchase alternative evaluation process" (Engel et al., 1995, p. 275). In correspondence with these authors, expectations will be treated here as 'predictive expectations'.

Perceived performance expresses the performance of the various product attributes as recognized by the customer. There is general consensus that expectations as well as perceived performance are not formed on an aggregate product level but for each product attribute separately (Oliver, 1993a; Oliver, 1993b). Halstead et al. (Halstead et al., 1994) state that this separate recognition allows for the assessment of the contribution each attribute makes to the overall satisfaction judgement.

According to Engel et al. (Engel et al., 1995), (dis)confirmation is the result of a comparison of expectations against perceived performance. Consumers make these comparisons using better-than, worse-than heuristics (Oliver, Rust, \& Varki, 1997). Positive disconfirmation occurs whenever a consumer's perceived performance exceeds his ${ }^{1}$ expectations, resulting in some degree of satisfaction. Negative Disconfirmation occurs when expectations exceed product performance, resulting in dissatisfaction. The intensity of the (dis)satisfaction experienced by the consumer is related to the intensity of the experienced (dis)confirmation (Patterson et al., 1997). Finally, under confirmation performance equals expectations, also resulting in satisfaction (Peter \& Olson, 1996). However, this can be regarded as a more neutral stance, not being very extreme (Engel et al., 1995).

The degree of satisfaction/dissatisfaction experienced by the customer in turn triggers an emotional reaction on his part as a result of the unexpected discrepancy between expectation and perceptions (Müller, 1998). This affective reaction then influences the customers' repurchase intentions, complaint behavior and word-of-mouth communications (Gupta \& Stewart, 1996; Patterson et al., 1997; Peter \& Olson, 1996).

According to De Ruyter et al. (De Ruyter, Bloemer, \& Peeters, 1997), a growing number of studies have also shown a direct influence of product performance on customer satisfaction. However, Halstead et al. (Halstead et al., 1994) provide an overview of studies showing a wide disparity of findings. In agreement with more current findings (Berger \& Mens van, 1997; De Ruyter et al., 1997; Oliver, 1993a; Oliver, 1993b), perceived performance will be treated here as exerting both, a direct and an indirect influence on satisfaction via (dis)confirmation. Figure 1 provides an overview of the Expectancy Disconfirmation Model.

\footnotetext{
${ }^{1}$ For the ease of writing, only the male form will be used while all propositions are equally valid for males and females.
} 


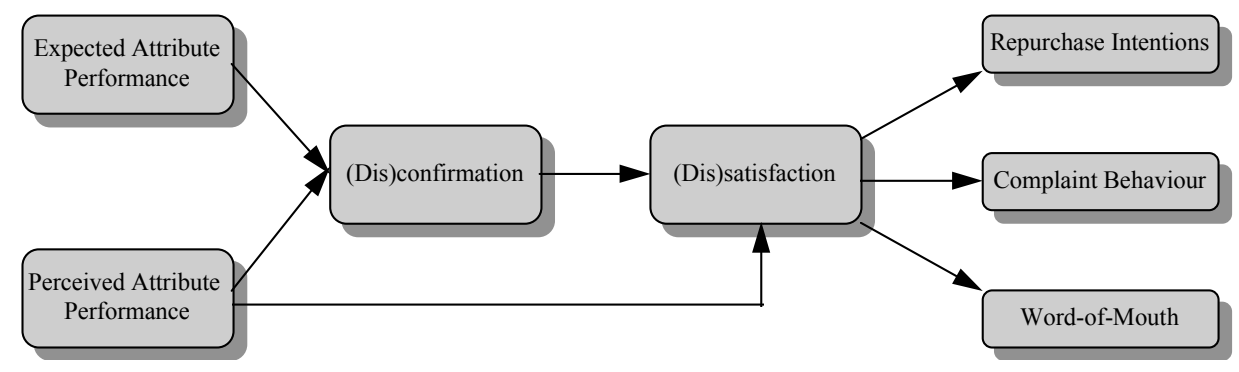

Figure 1: The Expectancy Disconfirmation Model

Source: Adapted from (Berger \& Mens van, 1997; Müller, 1998).

The scope of this paper has been restricted to customer satisfaction with products since satisfaction with services is not yet well understood in the marketing literature. The evaluation process for services is perceived as being more difficult (compared to products), based on different types and sources of expectations as well as based on the evaluation of the process as well as an outcome (Halstead et al., 1994). Specifically, prevailing in the service satisfaction literature is the dominant role of performance in service evaluation (Boulding et al., 1993; De Ruyter et al., 1997).

\section{Customer Satisfaction Measurement}

\subsection{The CS Research Process: Sampling Design \& Data Collection (Method)}

The measurement of customer satisfaction follows the steps described in general marketing research but each of them requires actions specific to CS research. A discussion of these specific actions would go beyond the scope of this paper. Figure 2 gives an overview of the seven steps of the research process. This paper is focused on performing steps 3 and 4 - Data Collection - using the Internet. Possibly, Step 2 - Explorative Investigation (i.e. assessing important product attributes) - could also be supported by online methods but this discussion is not within the scope of this paper.

According to Dutka, "telephone interviews and mail questionnaires are the chief methods of collecting data for customer satisfaction research" (Dutka, 1994, p. 61). Unless the sample size is very small, personal interviews are very cost- and time-intensive. Another drawback of this method is the interviewer bias, which is less intense during telephone surveys. Telephone surveys permit superior quality control, elicit large response rates and fast turnaround times (time between data collection and return). Mail surveys, in turn, are superior when customers are difficult to reach; they allow the customer to choose his own responding time and are less expensive. Their greatest drawback is the low response rate, which questions the representativeness of the returned questionnaires (Dutka, 1994; Fowler, 1997; Werner, 1997b). During the last ten years, computer-assisted telephone interviewing (CATI), computer-assisted personal interviewing (CAPI) and self-administered questionnaires have also been used in market research (Ronig, 1998).

The following section will introduce data collection methods for customer satisfaction research. 


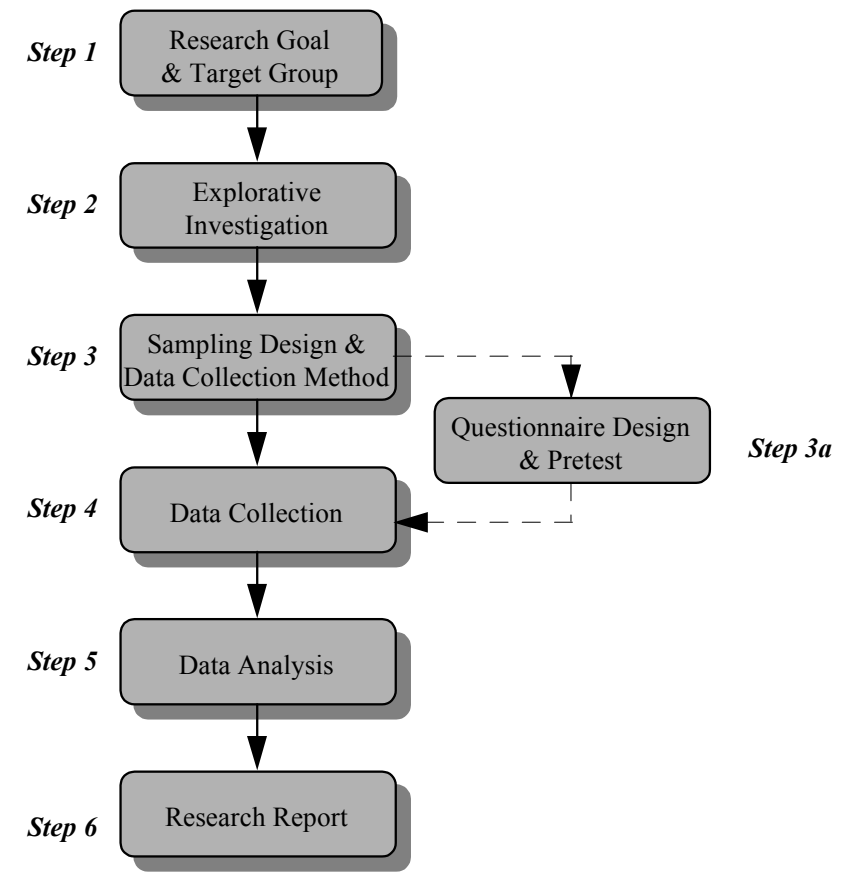

Figure 2: The CS Research Process

Source: Adapted from (Churchill, 1995; Homburg \& Rudolph, 1995).

\subsection{Measuring Customer Satisfaction}

A common problem with customer satisfaction measurement is the fact that in practice, a large amount of different approaches exist (Klingebiel, 1998; Ramos, 1996) of which a considerable number is not based on any theoretical foundation at all (Peterson \& Wilson, 1992). This can partly be attributed to the complexity of the (potential) concepts related to the construct of customer satisfaction. However, the success of any research for a large part depends on its theoretical foundations because "theory .. summarizes what is known about an object of study and states the uniformities that lie beyond the immediate observation .." (Cooper \& Emory, 1995, p. 43). Although the Expectancy Disconfirmation Model might not capture all the antecedents of customer satisfaction, it is based on extensive research and empirical validation and therefore superior to a purely intuitive approach. Because its aim is to investigate a precisely specified problem and the statement of the degree to which customer satisfaction is present, a CS investigation can be classified as descriptive research (Churchill, 1995). The CSmeasurement methods can be classified into two major categories: Objective methods and subjective methods. Objective methods measure observable quantities that are independent of the investigator's interpretation. Approaches include the analysis of sales turnover, market share, the degree of customer migration and the repurchase rate. However, these methods have two serious drawbacks: Firstly, their relation to customer 
satisfaction is not clarified theoretically; they are not included in the Expectancy Disconfirmation Model. Secondly, and related to the first point, it is also accepted throughout the literature that these methods are lacking validity (Lingenfelder \& Schneider, 1992; Töpfer, 1996)). Based on these arguments, subjective methods are often preferred to objective methods.

Subjective methods make use of a pre-defined construct of customer satisfaction and attempt to measure it via indicators (Lingenfelder \& Schneider, 1992). These methods can further be classified into attribute-specific methods and event-specific methods.

Figure 3 provides an overview of the most common approaches. Please note that within the subjective methods, only approaches relating to product satisfaction are taken into consideration.

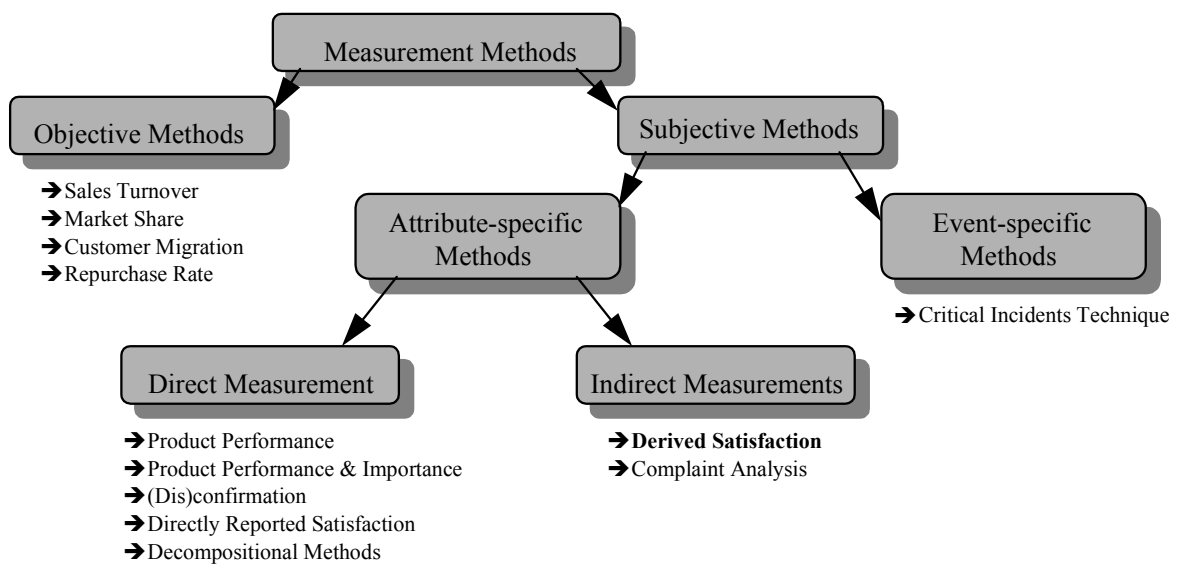

Figure 3: Methods of CS Measurement

\subsection{Attribute-specific Methods}

Attribute-specific methods are based on the assumption that the customer forms his product evaluation via individual product attributes (Eversheim, 1997). This view is in conformance with the Expectancy Disconfirmation Model. Attribute-specific methods are especially suitable for standardized, timely and costeffective measurements of features which are usually expected by the customer (routine attributes) (Eversheim, 1997). These methods can further be sub-classified into direct or indirect measurements.

Direct measurements approach satisfaction or its components in a straightforward way. Methods include the measurement of product performance, product performance and its importance, (dis)confirmation, directly reported satisfaction and the decompositional method (Bruhn, 1997; Kotler, 1994; Lingenfelder \& Schneider, 1992).

As its name implies, the analysis of product performance only takes the influence of performance but not that of (dis)confirmation into account and is therefore incomplete from a theoretical viewpoint. 
The measurement of (dis)confirmation in turn does not account for a separate influence of performance as modeled in the Expectancy Disconfirmation Model and is therefore inferior in situations where performance has a greater influence than expectations.

In the case of directly reported satisfaction, overall or multi-attribute satisfaction is measured via satisfaction scales. This approach shortens the measurement process because expectations and performance do not need to be measured separately. On the other hand, the disentanglement of the separate influences of (dis)confirmation and performance is inhibited which reduces its information content (Bruhn, 1997). Consequently, the separate influence of performance again cannot be accounted for.

Making use of the decompositional method, customers have to rate their satisfaction with different sets of prespecified combinations of product attributes. Attribute combinations are constructed in a way that they differ at the individual attribute level between groupings. Via a decompositional statistical analysis (e.g. Conjoint Analysis) the relative importance of the different attributes is assessed after the questioning has been conducted. This method does not allow for the separate assessment of (dis)confirmation and performance. Furthermore, by setting the individual product attributes at different levels, customers are expected to express their satisfaction with a product performance that they did not experience. According to the Expectancy Disconfirmation Model, this is not possible.

Indirect measurements do not measure satisfaction directly but only its antecedents (derived satisfaction) or infer from its consequences (complaint-analysis).

Derived Satisfaction measures the degree to which a certain attribute was expected as well as experienced (Bruhn, 1997; Kotler, 1994). This method acknowledges both influences on customer satisfaction and therefore also allows for the measurement of the separate influence of performance. However, according to the Expectancy Disconfirmation Model, expectations as an indirect influence on customer satisfaction are completely mediated through (dis)confirmation. Another option therefore is to measure the degree of (dis)confirmation as well as performance (Eversheim, 1997; Klingebiel, 1998; Lingenfelder \& Schneider, 1992). It follows that this approach best presents the Expectancy Disconfirmation Model because it accounts for the direct influence of (dis)confirmation and the possible separate influence of performance on satisfaction.

Furthermore, if supplemented with an evaluation of overall satisfaction, this method allows for the assessment of the importance of individual attributes after the data have been collected (Zacharias, 1998).

With regard to complaint analysis it should be noted that in general only about $5 \%$ of unsatisfied customers ever complain (Aaker, Kumar, \& Day, 1998; Eversheim, 1997; Kotler, 1994), which severely limits the method in is predictive ability.

Summarizing, the measurement of Derived Satisfaction was chosen as a good fit with the underlying theory of this paper.

\subsection{Event-specific Methods}

Event-specific methods rest on the assumption that a customer's satisfaction is largely dependent on the incidents he experienced with the company. These methods are based on so-called 'story telling' whereby customers are asked to report their experiences with the company/product in question in an unstructured way (Bruhn, 1997). The timing of the investigation is critical because customers must have been able to form an evaluation over the product as well as being able to remember that incident in detail (Eversheim, 1997; Töpfer, 1996). It should be noted that event-specific methods are very unlikely to generate a complete picture of the customers' satisfaction (Homburg \& Werner, 1996; Töpfer, 1996).

The Critical Incidents Technique focuses only on occasions where customers made exceptional, non-routine experiences (Stauss, 1995). Because the experiences under investigation are non-routine, they are believed to be stored in memory for a long time (Eversheim, 1997). Hayes (Hayes, 1992) adds to that point by stating that a critical incident is always specific to one single behavior or product characteristic. Customers are questioned via 
open-ended, standardized questions which facilitate the recall of these special incidents (Bruhn, 1997). Since the influence of critical incidents (exceptional, non-routine customer experiences) is not modeled within the Expectancy Disconfirmation Model this technique will not be further discussed in this paper.

To conclude, the measurement of Derived Satisfaction using (dis)confirmation is the appropriate approach to CS measurement within the context of the Expectancy Disconfirmation Model. All other methods only cover either (dis)confirmation or performance or measure satisfaction in a direct or incomplete way.

\section{Internet Research Methods}

Research on the Internet is being conduced by marketing and social researchers while "collection of primary information over the Internet is still in its incubation stage" (Aaker et al., 1998, p. 168). Methods can primarily be classified as reactive and non-reactive (Batinic \& Bosnjak, 1997a). While non-reactive methods are based on observation, they are not relevant for customer satisfaction measurements ${ }^{2}$. Reactive methods make use of survey questionnaires and online interviews. This section introduces the methods' main characteristics and advantages and disadvantages compared to traditional methods. In the next chapter, their suitability for the measurement of customer satisfaction will be discussed.

Table 1 summarizes the advantages and disadvantages of the Internet research methods that are discussed within this section.

\subsection{E-mail Surveys}

E-mail surveys use E-mail for the entire process of sending/receiving, completing and returning the questionnaire. E-mail surveys are the most comparable to traditional mail surveys because both are sent to a specific person and are completed by that person independently (Ronig, 1998; Selwyn \& Robson, 1998). When designing the questionnaire, ASCII formats should be used to ensure the proper representation of all characters while lines of maximal 65 characters prevent unwanted line breaks (Hambridge, 1995). Usually, enclosing of attachments containing multimedia is not advised because it increases downloading times. Moreover, the recipients might not have the necessary programs to view and open the attachments (Batinic \& Bosnjak, 1997a). Because many mailers strip header information, contact information should always be included on the bottom of the message.

To prevent publication of the recipients' addresses, the mailing list must be entered into the blind-carbon-copy field of the program (Ronig, 1998). A computer program can be used to prepare the questionnaire and distribution list and to extract the data from the replies. However, manual data entry can still be required due to varying layouts of the returned questionnaires (Gräf, 1998). The last point to mention is that unless an encryption device is used, E-mail on the Internet is not secure. In addition to their use in survey research, Emails are also commonly used for the questioning of experts on a specific topic (Hauptmanns, 1997; Naether, 1995; Naether, 1996).

The biggest advantages of E-mail surveys are their ease of administration, low cost compared to traditional survey methods and global reach. Furthermore, the majority of responses usually occur within the first three days after the mailing (Comley, 1996; Mehta \& Sivadas, 1995; Oppermann, 1995). Drawbacks are the often

\footnotetext{
${ }^{2}$ Non-reactive methods include server-log analysis and observations in Internet Relay Chats and Virtual Worlds (Batinic \& Bosnjak, 1997a). 
manually required data entry, messy return data and the fact that not everybody has E-mail, (Tuten, 1997). Another drawback is the minimum of layout options that can be used (Smith, 1997; Whatt, 1997), while some Email software limits the length of a message ((CustomerSat.com, 1999a; CustomerSat.com, 1999b, Tuten, 1997 \#364). Moreover, respondents can rewrite and delete questions, extend scales or simply delete unwanted mail (Krasilovsky, 1996). Most importantly, 'Netiquette' prescribes to keep unsolicited E-mail ('spam') at a minimum. Spam includes unsolicited advertisements and mass E-mailings, an out-of-context posting in a mailinglist/newsgroup, unusually large or frequent postings in a mailinglist/newsgroup and putting someone on a mailing list without consent and requiring him to 'opt-out' ${ }^{3}$. (Kurzman, 1998). A last point to mention is the response rate. Compared to traditional mail, some authors indicate that response rates are usually higher (Anderson \& Gansneder, 1995; Booker, 1996; Comley, 1996; Oppermann, 1995; Parker, 1992) while others report lower response rates (Agrawal, 1998; Kittleson, 1995; Schuldt \& Totten, 1994; Tse, 1998; Tse et al., 1995). Other authors (Bachmann, Elfrink, \& Vazzana, 1996; Mehta \& Sivadas, 1995; Rosenfeld, Booth-Kewley, $\&$ Edwards, 1993) have not found any difference in response rates. Some authors have suggested that response rates of E-mail and mail surveys are narrowing because people are getting increasingly comfortable in deleting unwanted mail (Bachmann et al., 1996; Tuten, 1997).

When used for the questioning of experts, the interviewer bias of a traditional face-to-face interview is eliminated and no additional interview transcript is needed. However, "a great deal of tacit information that would be conveyed in a conventional interview is lost" (Selwyn \& Robson, 1998). Although 'Netiquette' (Net Etiquette) proposes the use of Emoticons (e.g. ;-) ) to express nonverbal reactions, it is questionable whether they can substitute the non-linguistic cues of a face-to face conversation (Selwyn \& Robson, 1998). Lastly, immediate probing into experts' answers is not possible due to the asynchronous character of the medium

\subsection{WWW-Surveys}

The programming of a WWW survey lets the researcher choose from a large amount of options. Question answering modes that can be used include checkboxes, radio buttons, drop-down lists for single or multiplechoice and conventional text fields (one to multiple lines). Furthermore, adaptive questioning (subsequent questions asked depend on the respondent's answers to previous questions), forced answering modes and realtime data verification and re-entry can be achieved. Adaptive questioning can be realized after every batch of questions or following immediately after each question (Kehoe \& Pitkow, 1997). Questionnaires can then consist of various pages which are linked so that the adapted questioning can be realized as effectively as possible (Gadeib, 1999). Moreover, questionnaires can be made 'lively' by inserting pictures, video clips, audio and $3 \mathrm{D}$ animations while questions can be put into a randomized order to prevent question order effects. To restrict access to a pre-selected group, passwords can be used (Batinic \& Bosnjak, 1997a). If respondents take part in a longitudinal survey and keep their original passwords, their previously submitted demographic information can be filled in to make the survey more convenient for them (Kehoe \& Pitkow, 1997). Agrawal (Agrawal, 1998) states that an increasing tendency is to use online incentives (e.g. a prize redemption code sent via E-mail that allows the respondent to order a product for free). However, this in turn might increase the tendency of multiple submissions by one person. Related to this point, Carl (Carl, 1998) advises to use only immaterial incentives.

\footnotetext{
${ }^{3}$ The EU Directive of May 20 concerning Distance Contracts (97/7/EC) prescribes grant respondents the possibility to 'opt-out' from a mailinglist. Member states are furthermore free to introduce more stringent provisions (e.g., the requirement to 'opt-in') (EuroCauce, 1999).
} 
After having been programmed, a WWW survey is placed on a Web server on the client's or the research company's location. Since it is unlikely that respondents find the survey by chance, it needs to be promoted (Bandilla \& Hauptmanns, 1998; Coomber, 1997; Werner, 1997b). Promotions can include links to other pages (also banners), entries in search engines or ads in traditional print media (Werner, 1997b). Moreover, questionnaires can be posted in newsgroups and mailing lists (Ronig, 1998). For reasons of data protection, a researcher should ensure to use secure-server technologies within the WWW (Batinic \& Bosnjak, 1997a). Returned data can automatically be transferred to a data analysis program (Batinic, 1997). Furthermore, "data base queries can be programmed to give periodic reports of the data to-date, including statistical analyses" (Carver, Kingston, \& Turton, 1998; Whatt, 1997). Summary statistics of the respondents' input can be provided instantaneously and be used as an incentive for their participation.

\begin{tabular}{|c|c|c|}
\hline Research Method & Advantages & Disadvantages \\
\hline E-mail Survey & $\begin{array}{l}\text { Administrative ease, low cost, global reach, } \\
\text { fast response times }\end{array}$ & $\begin{array}{l}\text { limited penetration, } \\
\text { undesirability of unsolicited E- } \\
\text { mail, minimal layout options, } \\
\text { length restrictions, respondents } \\
\text { can alter the questionnaire } \\
\text { which requires manual data } \\
\text { transfer }\end{array}$ \\
\hline Expert Questioning via E-mail & $\begin{array}{l}\text { all advantages of E-mail surveys, no } \\
\text { interviewer bias, instant interview transcript }\end{array}$ & $\begin{array}{l}\text { loss of tacit information, no } \\
\text { immediate probing into } \\
\text { answers }\end{array}$ \\
\hline WWW-Survey & $\begin{array}{l}\text { all advantages of E-mail surveys, overall } \\
\text { effectiveness, visual appeal, automatic data } \\
\text { transfer, possible report of online results } \\
\text { after each survey-submission, summary } \\
\text { statistics can be used as an incentive to } \\
\text { participate }\end{array}$ & $\begin{array}{l}\text { limited penetration, respondent } \\
\text { pays for being online, self- } \\
\text { section bias, non- } \\
\text { representativeness, without } \\
\text { controlled access: multiple } \\
\text { submissions possible and no } \\
\text { accurate response rate, } \\
\text { depending on the browser } \\
\text { used: differing layouts, } \\
\text { increased down-loading times, } \\
\text { Java incompatibility }\end{array}$ \\
\hline Online Focus Group & $\begin{array}{l}\text { Global reach, no travel (costs) for } \\
\text { participants, easy control of dominant } \\
\text { participants, no environmental influence of } \\
\text { a studio, } \\
\text { Instant interview transcript }\end{array}$ & $\begin{array}{l}\text { no control over the respondents } \\
\& \text { situation, nonverbal cues } \\
\text { cannot be observed, unclear } \\
\text { influence of anonymity on the } \\
\text { honesty of answers people with } \\
\text { poor typing abilities might be } \\
\text { intimidated, answers can be } \\
\text { less spontaneously }\end{array}$ \\
\hline Targeting Internet-specific Groups & Advantages & Disadvantages \\
\hline $\begin{array}{l}\text { Posting in Newsgroups/ } \\
\text { on Mailingslists }\end{array}$ & Increased awareness of the survey & $\begin{array}{l}\text { low response rate, cross- } \\
\text { postings violate Netiquette, no } \\
\text { commercial use allowed on }\end{array}$ \\
\hline
\end{tabular}




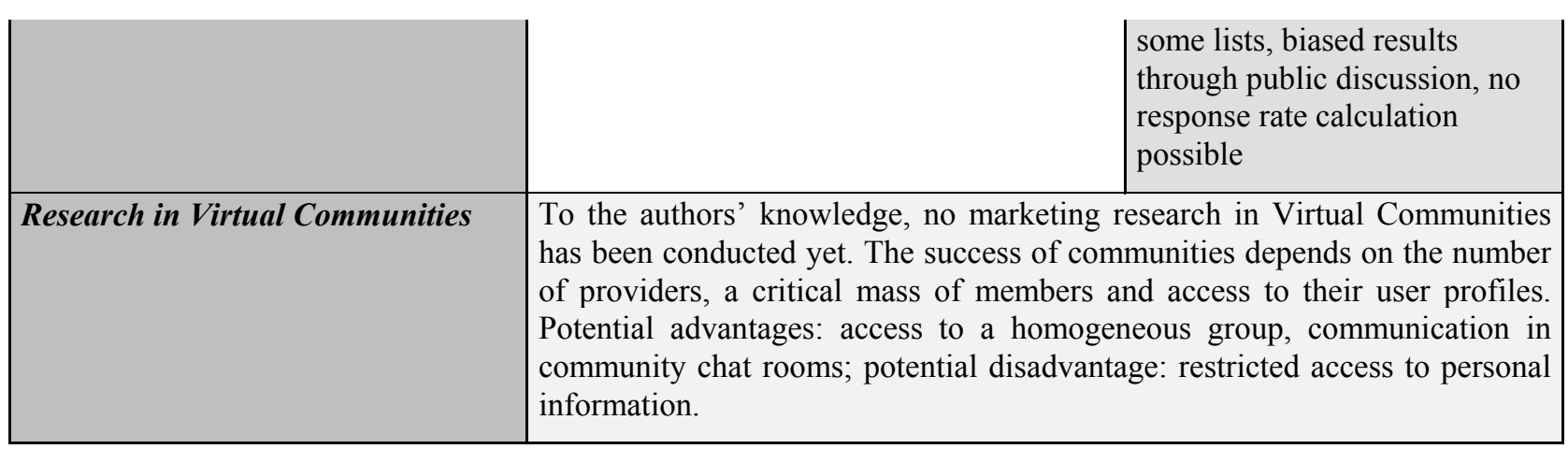

Table 1: Advantages and Disadvantages of Internet Research Methods

The major advantages of this method are its relatively low cost compared to other traditional methods, global reach, overall effectiveness (e.g. automatic question skips and plausibility checks) and visual appeal (Carver et al., 1998; Tuten, 1997). Furthermore, manual data entry is completely eliminated, so data are accurate. Also, the majority of responses occur within 2-3 days, while after the first week, responses decrease significantly (Batinic \& Bosnjak, 1997b). Cost savings compared to traditional methods are achieved mainly through the ease of distribution and data collection (Agrawal, 1998). Lastly, respondents can complete and return the questionnaire at any time they find convenient.

The largest problem when using WWW questionnaires is that of self-selection, meaning that not every person in the population has the same chance of finding the survey (Werner, 1997a). Another drawback is the sample bias because the Internet population is still relatively small and non-representative for the general population (Aaker et al., 1998; Tuten, 1997). It follows that the construction of a random sample is possible only with controlled access and personal invitations. Furthermore, without access restriction to the questionnaire, there is no quality control over the sample of respondents participating and multiple submissions by one person are possible. A related problem is the determination of response rates in surveys without restriction. Usually, the quotient of questionnaires sent and received is taken as the response rate. However, three problems center on this method: Firstly, only people who actually requested the questionnaire (as opposed to those who saw its promotion) are counted. Secondly, multiple submissions by the same person are possible. Thirdly, when the questionnaire is saved on a local proxy server, the exact amount of requested questionnaires cannot be controlled (Batinic \& Bosnjak, 1997a). Moreover, the response rate can be influenced by the questionnaires' graphical designs because those might differ depending on the respondents' browser. In addition, the usage of multimedia or adaptive questioning can increase downloading times substantially. Lastly, different browsers handle Java applets, which are used for adaptive questions, differently (Kehoe \& Pitkow, 1997).

A general issue regarding online surveys is that the respondent himself incurs the costs for the completition of the survey (Bandilla \& Hauptmanns, 1998). Urgent research is therefore necessary to investigate this potential influence on the response rate.

\subsection{Online Focus Groups}

According to Agrawal (Agrawal, 1998, p. 196), "online Focus Groups ... are yet to attain popularity". However, some marketers (NFO, ; NFO, , CustomerSat.com, 1999 \#419) have already started using them. In online Focus Groups information is exchanged in the form of text. After having received the URL and a password, participants $\log$ onto the webserver of the moderator and interact via the sending and receiving of messages (Hagenhoff \& Pfleiderer, 1998). Recruitment of participants can be made via telephone, E-mail or the automatic invitation of every n-th visitor of the company Web-site (Hagenhoff \& Pfleiderer, 1998; Levy, 1998). Each 
respondent anonymously answers the moderator's question simultaneously by typing his answer into a field provided for this purpose (Hagenhoff \& Pfleiderer, 1998).

The moderator can 'broadcast' messages visible to all participants or 'whisper', meaning that only a targeted recipient can read his message. This enables the moderator to probe into points of interest (NFO, ). Readily typed questions can be 'cut and pasted' in order to save time. Using the 'pause' mode, answers can be suppressed until everybody in the round has responded (Hagenhoff \& Pfleiderer, 1998). Live-links to other Web-sites or broadcasting of multimedia (pictures, audio, video) can be made available in split-screen mode (Levy, 1998).

An advantage of this method is that respondents can participate without leaving their home (in remote geographical locations), which is especially advantageous in cross-national studies. The lack of environmental influences of a studio is sometimes believed to elicit more honest and spontaneous answers (Hagenhoff \& Pfleiderer, 1998; Solomon, 1998). Moreover, dominant participants can be controlled more easily and the interviewer influence is reduced (Götte \& Kümmerlein, 1996). All answers can be saved without the potential information loss of a traditional group since no additional transcript needs to be produced (Levy, 1998). Furthermore, communication is conducted in parallel "which may allow people to share information ... more quickly" (Dennis, Valacich, Connolly, \& Wynne, 1996). Lastly, costs are usually lower due to reduced traveling expenses (CyberDialogue, 1998; NFO, ).

However, the 'advantage' that respondents do not need to leave their home is at the same time the largest problem one has to deal with. Because the laboratory condition of a traditional Focus Group cannot be replicated, the moderator has no control over the situation in which the participants are at the moment, whether their attention is undivided and if their participation is independent of other people's immediate influence. Naether (Naether, 1996) further states that answers in online Focus Groups are always controlled and that spontaneity is therefore not possible. A related problem is the question as to how far anonymity leads to dishonest answers (Grüne, 1998; Solomon, 1998). Furthermore, because some people might not be able to type fast, important thoughts might not be expressed, while the ability of Emoticons to substitute nonverbal reactions is questionable. Sketches and drawings that might be part of a product-related discussion cannot be displayed in a text-based online group. As was the case with WWW surveys, the costs for being online are borne by the respondents. Since online Focus Groups usually last around one hour (Solomon, 1998), the company by all means should reimburse the participants' costs.

Another serious point to mention is that no systematic investigations of online Focus Groups are yet available. Moreover, researchers of general computer-mediated communication have found varying results. After having conducted a laboratory experiment concerning the effect of anonymity in Internet relay chats, Sassenberg and Kreutz (Sassenberg \& Kreutz, 1997) found that with decreasing knowledge about the other participants in an online communication, the individual participant's orientation focuses more on his individual attitudes and needs. According to Briggs et al. (Briggs, Nunamaker, \& Sprague, 1998), recent studies have found that convergence is much more difficult with distributed than face-to-face groups. However, according to Kiesler and Sproull (Kiesler \& Sproull, 1992), experiments have shown that, compared with a face-to-face meeting, a computer-mediated discussion leads to more equal participation among group members and status equalizing effects among other things. Sassenberg (Sassenberg, 1999), in turn reports that in comparisons of computermediated and face-to-face communications, contradictory results have been obtained in that a stronger mutual influence of respondents was sometimes found in computer-mediated and sometimes in face-to-face communication.

\subsection{Internet-specific Target Groups}

Another characteristic of the Internet is the fact that it is 'populated' by some target populations that cannot be reached offline with the same ease. These groups include subscribers to newsgroups or mailinglists and 
members of Virtual Communities. We will discuss the use and implications of these groups shortly in the following sections.

\subsubsection{Newsgroups and Mailinglists}

Subscribers to newsgroups or mailinglists can be recruited as survey participants (Aaker et al., 1998). Using this method, an invitation to a WWW-survey is placed in the newsgroup or on the mailinglist. When E-mail questionnaires are used, the researcher can choose between directly placing the questionnaire or only placing an invitation (Bandilla \& Hauptmanns, 1998).

While recent evidence indicates that surveys in newsgroups are usually characterized by a low response rate, 'cross-postings' in various groups to heighten the response rate are recommended (Bandilla \& Hauptmanns, 1998; Batinic \& Bosnjak, 1997a). However, excessive ‘cross-postings' and postings of unrelated topics violate 'Netiquette', while many newsgroups do not allow commercial content. Moreover, questionnaire length is a critical issue since newsreaders usually report the number of lines next to its header. Another drawback of this method is the likely emergence of a public discussion of the survey that would bias its result trough its uncontrolled influence (Batinic \& Bosnjak, 1997a). In addition, the refusal rate cannot be determined because the message is not saved on a central server but on all news-servers around the world which offer the particular newsgroup (Batinic \& Bosnjak, 1997a). Lastly, and most important in a CS context, the results of the survey are not representative due to the self-selection of the respondents.

\subsubsection{Virtual Communities}

Virtual Communities are a promising target for marketers. Paul and Runte (Paul \& Runte, 1998) state that these communities offer superior possibilities for online marketing and predict that they will increasingly function as an intermediary between providers and consumers. While Kannan et al. (Kannan, Chang, \& Whinston, 1998, p. 39) state that "the business model for supply of information products from e-communities and individual consumers is still evolving", Virtual Communities can, under certain conditions, also offer possibilities for online marketing research. This can be translated into significant revenue potential for Virtual Communities (Kannan et al., 1998).

Paul and Runte (Paul \& Runte, 1998) acknowledge that the success of Virtual Communities depends on how fast a critical mass of members, their preference- and transaction-profiles and providers themselves accumulate. Related to that point, Hagel and Armstrong (Hagel III \& Armstrong, 1997) hypothesize that communities will eventually be a vital part of the total sales of a company.

Because of their novelty and the immaturity of these communities, it is difficult to make a statement regarding their suitability for online research in general. An advantage of these communities is that buying power is concentrated in relatively homogeneous groups, which makes a focused targeting very easy. Specific consumerpreferences can be generated through the tracking of their online behavior or through the direct questioning of their preferences when joining the community. According to Paul and Runte (Paul \& Runte, 1998), many current communities choose the latter approach. The authors argue that product offerings can be tailored to each member based on his preference information, which then leads to the closer binding of the member to the community.

Moreover, while personal communication between members can be realized in chat-rooms, these rooms can also be used for context-related and moderated 'public' or restricted discussions.

More ambiguous are the product/service-specific word-of-mouth communications between the community's members. While they can be advantageous whenever the opinions are positive, negative experiences are also discussed openly which can have a detrimental effect for the supplier. Furthermore, Virtual Communities will eventually have to provide access to competing product/service providers in order to keep their members. This could make it easier for competitors to monitor the research efforts and themes of the conducting company. Lastly, Hagel and Sacconaghi (Hagel III \& Sacconaghi Jr., 1996, p. 31) warn that "privacy is likely to rise as a 
significant policy issue". One will have to wait if members in the future will still be willing to provide a great deal of personal information and in how far the tracking of their movements will be possible.

\subsection{Summary}

Concluding, with its growing user profile, the Internet is an interesting new medium for customer satisfaction measurements. Internet research methods include E-mail surveys, WWW-surveys and online Focus Groups. Common advantages of E-mail- and WWW-surveys include administrative and response speed, cost savings and global reach of respondents. Their greatest common disadvantage is the non-representativeness for the larger population and the self-selection of respondents. While both methods can be used for survey research, it has been found that E-mail surveys have serious disadvantages compared to WWW-surveys. WWW-surveys in turn offer opportunities that are not available with any other method. However, unless access is restricted to a known population, probability sampling is impossible when using the World Wide Web.

The conduction of online Focus Groups in turn is not (yet) advisable because next to its many other disadvantages, the moderator cannot ensure that the participants' attention is undivided and independent of other people's influence. Accordingly, online Focus Groups will not be discussed further in this paper.

Target Groups specific to the Internet include members of Virtual Communities and subscribers to newsgroups and mailinglists. While Virtual Communities might be suitable for online research in the future, postings in newsgroups/on mailinglists are not advisable due to the large number of disadvantages and the nonrepresentativeness of the survey results. For these reasons, Internet target groups will not be discussed any further in this paper.

\section{Customer Satisfaction Measurement on the Internet}

CS studies on the Internet are very new phenomena: The first worldwide customer satisfaction survey was conduced on the Internet only two years ago, in 1997 (Slevin \& Chisholm, 1997). In this section the usefulness of the Internet research methods for customer satisfaction measurements will be evaluated from a theoretical viewpoint. In the previous section we have identified E-mail and WWW surveys appear to be the most appropriate options for online CS research. We will now discuss how and when these instruments can be used. First, a general discussion of online measurement of derived satisfaction will be followed by the implications for E-mail surveys, WWW surveys and a combination of both. Throughout the section, recommendations are derived from the literature and combined in a decision-making framework (Figure 3).

\subsection{Online Measurement of Derived Satisfaction}

As has been explained earlier, measurements of Derived Satisfaction are conducted in order to obtain a representative picture of the current satisfaction level of the customers. However, it has been explained in the previous section that representative surveys on the Internet are only possible for a defined population with access to the Internet. Ronig (Ronig, 1998) concludes that representative Internet surveys can (so far) only be conducted within closed groups or when an offline quota of the population under investigation is available.

Recommendation 1: For online measurement of CS, access of all customers to the survey medium (Email or WWW) must be assured.

In order to be conducted in a standardized and timely manner, Derived Satisfaction can be measured via E-mail or with a WWW survey. 


\subsubsection{E-mail Surveys}

Independent of the online method chosen, the question of customer access must always be clarified first. While the population of interest in a CS research are the customers and the appropriate sampling frame is the customer database, customers' E-mail addresses should be readily available or easy to access. However, not all customers need to have access to E-mail. Often $20 \%$ of a company's customers generate about $80 \%$ of the profitable sales, which makes them prime targets in a CS survey (Hanan \& Karp, 1989). Therefore, probability sampling should in general be possible when surveying via E-mail. However, when there is only quota information about the customers available (e.g. when selling a mass-product), E-mail addresses are not easy to acquire. Furthermore, the sending of mass E-mails on the basis of E-mail directories is not acceptable according to 'Netiquette' (Batinic \& Bosnjak, 1997b). In the same vein, the European Society for Opinion and Marketing Research (Esomar, 1999a) also urges to keep unsolicited E-mail at a minimum.

While some authors conclude that a relationship with the group of individuals to which an E-mail survey is sent is advisable (Batinic \& Bosnjak, 1997b; Schonland \& Williams, 1996), Kurzmann (Kurzman, 1998) states that "spam often seems worse when it comes from someone you know and into which you've placed your trust". He even suggests that companies should adopt the policy of never purchasing from other companies who are sending out 'spam'. Moreover, while according to the EU Directive concerning Distance Contracts (97/7/EC) a person not wishing to receive unsolicited E-mail has to actively 'opt-out', the directive also states that memberstates may introduce more stringent provisions ${ }^{4}$ (EuroCauce, 1999). In Australia, Europe, and North America coalitions against 'spam', which are lobbying government legislation, have already been formed.

It follows that unsolicited E-mail surveys have large potential to negatively influence a customer's perception of the company sending the survey. The point seems especially severe in a CS context because the negative affect created by unsolicited E-mail could temporarily influence a customer's ratings negatively. Peterson \& Wilson (Peterson \& Wilson, 1992), in their meta-analysis of CS studies found that mood and satisfaction ratings tend to correlate, although the specific influence of mood has not yet been clarified. Summarizing these insights, the following recommendation can be given:

\section{Recommendation 2: E-mail surveys should only be sent out with the explicit prior consent of the customers.}

While a customer's consent can be asked for with regular mail or via the phone, the most convenient way is to ask him via E-mail, which again raises the 'spam' issue. Within its guidelines for Internet marketing research, Esomar (Esomar, 1999a) prescribes to "reduce any inconvenience or irritation such E-mail might cause to the recipient by clearly stating its purpose in the first sentence and keeping the total messages as brief as possible". Relating to this point, Kurzmann (Kurzman, 1998) states that a short, individually e-mailed message to customers seems acceptable. Another issue is the sending of E-mails to unknown customers whose addresses have been obtained from an E-mail directory list. 'Netiquette' and Caube (CAUBE, ) regard this as violent misbehavior.

Recommendation 3: Using E-mail to ask for customer consent should be acceptable when there is an existing business-relationship and the message is short and individually addressed.

\footnotetext{
${ }^{4}$ As an example, in Germany, customer data may only be used for marketing research when the customer has provided his explicit consent (Werner, 1998).
} 
Another issue to deal with is the fact that E-mail questionnaires can only handle a certain amount of lines. While this in part depends on the program used (by the respondent), E-mails containing more than 100 lines are considered to be 'long' by 'Netiquette' (Hambridge, 1995). While one also has to restrict oneself to 65 characters per line, the available space is filled very fast due to three reasons: Firstly, the measurement of Derived Satisfaction as an indirect measurement involves asking two questions for each product attribute. Secondly, when the company wants to benchmark its performance against that of the competitors, another question regarding competitors performance (for each product attribute) needs to be asked. Lastly, answering scales used are usually interval scales (e.g. better then/worse than expected) which usually range from 5 points to 10 points, thereby furthermore contributing to the length of the questionnaire. It can be concluded that given that recommendations 1 and 2 are not violated, E-mail surveys can be used for short, single-product surveys.

Recommendation 4: E-mail surveys should only be used for short, single-product surveys.

\subsubsection{WWW Surveys}

WWW-surveys offer the researcher advantages, which are not available with traditional methods or E-mail surveys. While many of them (e.g. adaptive questioning and forced data entry) can also be realized with computer-assisted surveying (CAPI or CATI), others are unique (e.g. global reach, administrative and response speed, and low cost especially compared to CAPI and CATI). Cost advantages can be especially large in a CS context where the questionnaire is only programmed once and then used several times in a longitudinal survey. Furthermore, the programming task itself is easier compared to the programming of a CAPI or CATI questionnaire (Werner, 1997b).

However, as was the case with E-mail surveys, a prerequisite for conducting WWW-surveys is the target populations' access to the medium. While this information can be obtained whenever a customer database is available, its gathering might take a considerable amount of time, or, depending on the closeness of the relationship, customers might feel bothered and simply do not submit this information. However, if customer access can be assured, a random sample can be drawn. Furthermore, the password-protection of the questionnaire allows the calculation of exact response rates, the prevention of multiple responses by one person and the exclusion of people outside the target group. Whenever customer access is not previously controlled for, the representativeness of the results must be questioned and the response rate cannot be calculated.

Recommendation 5: Given that a sampling frame is available, WWW surveys must be password protected and access of the target population to the WWW must be assured (R1).

The need to gather information about the customers' access to the WWW is completely eliminated when the product is exclusively sold online. In this case, without access to a sampling frame, a random sample of customers can be drawn by exposing the survey to every n-th visitor of the homepage (Pfleiderer, 1997). By asking every respondent about the frequency of his visits, the mean visits per $n$-th visitor can be calculated. The hits on the page within a given time-frame can then be divided by the number of mean visits per respondent to get an indication of how many individuals visited the site within the time frame (Hagenhoff \& Pfleiderer, 1998). This allows for an approximation of a response rate and weakens the problem of self-selection (Werner, 1997a). In order to reduce multiple responses, their previous participation within a given time frame can also be asked for. Lastly, the respondents can be offered the opportunity to be contacted via E-mail in order to fill out the survey at a later time (Pfleiderer, 1997).

It should be noted however that not every customer has the same probability to be included while multiple responses by a customer cannot always be prevented. The company conducting the survey could also consider giving up the anonymity of the respondents by requiring them to enter e.g. their customer number in order to 
prevent multiple submissions. Because of these problems, the method should only be chosen if a customer quota has to be met and accordingly no sampling frame is available.

However, if the company conducting the survey has neither a customer database available nor exclusively sells via the web, the situation is very different. In this case, the offline customer quota can be compared to the current user profile on the web. However, even when the quota can be met on the web, Bandilla (Bandilla, 1997) warns that customers in both groups can still be different on many characteristics (e.g. demographics, interests, and preferences). While a combination of online and offline methods seems to be a solution to the problem, we will explain later why this is not (yet) advisable.

It follows that the web is not suitable for a measurement of Derived Satisfaction when no sampling frame is available and the product is not exclusively sold online.

\section{Recommendation 6: Given that no sampling frame is available, a quota sample can be taken from the homepage only if the products are exclusively sold online.}

Given the fact that the product is not sold exclusively online and the customers have access to the WWW, they need to be invited to the survey. Invitations can be generated by establishing links to other pages, entries in search engines, postings in newsgroups and on mailinglists and via ads in traditional media. While these methods, with the exception of excessive cross-postings in newsgroups/on mailinglists do not violate 'Netiquette', they do not allow for a controlled access to the questionnaire, which has been required in recommendation 4. Furthermore, because of the disadvantages stated earlier, postings in newsgroups/on mailinglists are not advisable in general.

Controlled access can be assured by sending personal invitations via telephone, mail or E-mail. The most advantageous approach is to send an E-mail, which contains the URL of the survey in its body. By clicking on this URL, customers are directly transferred to the questionnaire. Furthermore, it can be combined with a customer-specific password (PRI) so that customers do not even have to enter a password anymore (CustomerSat.com, 1999a, CustomerSat.com, 1999 \#418). However, it has been concluded earlier that this type of invitation is only acceptable if individually addressed to a customer who is engaged in an existing businessrelationship with the company conducting the survey.

Another advantage of the WWW-survey in combination with E-mail invitations is that it actually gives the company two options to ask the customer if he may be contacted in future surveys. While one possibility to 'optin' can be placed in the E-mail invitation, the other one can be added to the WWW-survey itself. This gives the respondent the opportunity to opt-out if he wishes to do so without having to access the survey. If he however decides to participate he does not have to separately submit his consent.

\section{Recommendation 7: E-mail is the most convenient method to invite customers to the $W W W$-survey given that the message is short and individually addressed.}

A major advantage of the World Wide Web for the measurement of Derived Satisfaction is the possibility to extract a maximum amount of information while keeping the questionnaire as short as possible. This can be achieved with the help of forced choices and adaptive questioning. The advantages of adaptive questioning in a CS context are likely to be greatest with multi-product surveys. Before the questions related to one product are presented to a customer, he can be asked if he is familiar with the product under question. Should that not be the case, the batch of related questions can be skipped completely, thereby markedly decreasing questionnaire length. The usage of forced entry ensures that no question has been missed and completely eliminates the 'missing value' problem of mail surveys. While Churchill (Churchill, 1995, p. 745) states that "a significant incidence of no information on any item might in itself be insightful", this method ensures that all questions are answered and that the reason for 'missing values' is always known. 


\section{Recommendation 8: WWW-surveys are better suited for multi-product surveys or surveys with many product attributes than E-mail surveys.}

Lastly, a WWW-survey can be programmed in a way that online results can be inspected after each incoming questionnaire. While this is convenient for surveys that provide mean values and distributions as their only results, the measurement data of Derived Satisfaction are usually subject to more sophisticated analyses. However, because of the frequent skew of response distributions of CS measurements, the normality of the data needs to be checked before any parametric tests can be conducted. Moreover, the derived importance of product attributes cannot be calculated before the data set is complete.

To summarize, data from the measurement of Derived Satisfaction are subject to analyses that can only be undertaken when all questionnaires have been submitted. Furthermore, if an external marketing research company conducts the research, it might have to assist its customer in interpreting the results (e.g. of a regression analysis).

\section{Recommendation 9: Survey-results should only be submitted online after the data set is complete and all} analyses have been made.

\subsubsection{Comparability/Combination of Methods}

It became clear in the previous sections that both, E-mail and WWW-surveys are only suitable for the measurement of Derived Satisfaction when specific conditions are met. A natural solution would therefore be the combination of methods to achieve a broader coverage of the population whenever the customers' access to either medium is only moderate. However, very little research on the comparability of methods has yet been undertaken. Agrawal (Agrawal, 1998, p. 198) states that there currently is a "lack of validation evidence and comparative studies in which web surveys are compared with traditional telephone or mail survey technology". Unfortunately, the comparability of E-mail and Web-surveys has also not been clarified yet.

According to Batinic (Batinic, 1997), a number of studies indicate that electronic surveys (not Internet surveys) are comparable to traditional paper and pencil surveys within limits. Unfortunately, he does not state what these limits actually are. Tuten (Tuten, 1997) also states that overall, computer administered surveys generate comparable results to traditional paper and pencil surveys with the added benefit of longer and more disclosing responses to open-ended questions. Having compared the results of a disk-by-mail and a paper-and-pencilsurvey, King and Miles (King Jr. \& Miles, 1995) conclude that administration mode has no effect on measurement equivalence. Bosnjak and Batinic (Bosnjak \& Batinic, 1997), after their comparison of a WWWand a paper-and-pencil survey also report that both versions have the same reliability. According to Breitner and Batinic (Breitner \& Batinic, 1997), the combination of various methods might lead to the best success over time. Several authors however question the comparability of paper and pencil and computerized tests. Kiesler and Sproul (Kiesler \& Sproull, 1986), in their early research found that respondents showed more sincerity in E-mail surveys compared to mail-surveys. According to Buchanan and Smith (Buchanan \& Smith, 1999), several studies have found increased levels of self-disclosure in computer-administered tests and differing response patterns between traditional and computerized tests. The authors (p. 129) summarize that the "equivalence of computerized and traditional versions cannot simply be assumed but must be demonstrated for each test".

Lander (Lander, 1998) agrees by stating that response distributions differ between surveys conducted online and with traditional methods. She further hypothesizes that there might be specific characteristics of the Internet that can be accounted for these response rate differences in distributions.

It follows that with only limited availability of comparative studies, no consensus has been reached so far. The problem of data comparability is especially important in a CS context because differences between response 
patterns had been found earlier in the meta-analysis of Peterson and Wilson. "Satisfaction data collected using different (data collection] modes are not comparable; on average, oral administration of satisfaction questions ... appears to increase satisfaction ratings by approximately 10-12 percent relative to self-administration" (Peterson \& Wilson, 1992, p. 64).

Based on these arguments, the following recommendation can be stated:

\section{Recommendation 10: Online survey methods should not (yet) be combined with traditional methods.}

Even less literature can be found on the comparison of E-mail and WWW-surveys. Schillewaert et al. (Schillewaert et al., 1998) in comparing responses to a WWW survey and an E-mail survey while measuring attitudes towards the web report that user responses do not differ between the two methods. Making the same comparison, Bosnjak and Batinic (Batinic \& Bosnjak, 1997a) conclude that WWW-surveys and E-mail surveys generate data having the same reliability, while a tendency of more 'socially acceptable responding' was found in E-mail surveys. However, it should be noted that the WWW-survey used by the authors allowed anonymous responding, which is likely to at least partially contribute to this difference.

While conducting a CS study on the Web, Bogner (Bogner, 1996) hypothesized that especially critical customers would return the questionnaire. However, he found that answers to his questions were mainly positive. While no conclusions can be drawn from only a single study, this again raises the question if the skewed response distribution that had been found in traditional surveys might occur in online surveys as well. To conclude, the limited evidence available indicates that E-mail and WWW-surveys might have the same reliability if the topic under investigation is not a sensitive one. However, especially interesting in a CS context is the question if both, none, or only one of the two methods is also subject to response skews. Until results of comparative studies on this issue amount, a combination of methods for the measurement of Derived Satisfaction is not advisable.

\section{Recommendation 11: E-mail surveys should not (yet) be combined with WWW-surveys.}

Summarizing, eleven recommendations regarding the choice and use of online CS surveys methods were made. As has become clear from the above discussion, representative measurements of Derived Satisfaction on Internet are only possible when very specific conditions are met. On top of this concern for representativeness, other characteristics of the online methods also need to been taken into account.

\subsection{The Decision-Making Framework}

The most comprehensive decision to be made in the online research process is the choice of a data collection method. A decision-making framework to guide the selection of an online method is presented in Figure 4. The framework provides an overview of the recommendations made in the previous sections.

-insert Figure 4 approximately here (see attached)

First, the customers' access to the WWW and/or E-mail needs to be assured (R1). In the case of limited penetration of either medium, online and offline methods as well as E-mail and WWW-surveys cannot (yet) be combined (Recommendations 10 and 11). Secondly, the length of the survey needs to be controlled for. Because WWW-surveys offer advantages, which are not available to E-mail surveys, they are clearly superior from a theoretical standpoint, especially when many questions need to be asked (Recommendation 8).

E-mail surveys can still be considered when the survey to be conducted is short (Recommendation 4) and the company is engaged in an existing business relationship with its customers (Recommendation 3). Furthermore, 
the customers' consent to receive the survey must be asked for, which can be done with a short and individually addressed E-mail (Recommendation 2).

If the WWW is chosen as the administrative method, the subsequent proceedings depend on the sample to be taken. If a sampling frame is available, only a password-protected survey can be posted (Recommendation 5). Customers are invited via E-mail (with the URL of the survey in its body) only under the condition that there is an existing relationship between the company and its customers (Recommendation 7).

Should that not be the case, invitations can still be made using offline methods. However, Schillewaert et al. (Schillewaert et al., 1998, p. 313), after having compared different recruitment methods to a WWW-survey conclude that "the advantage of fast electronic data collection is lost due to the mix of a physical recruitment medium and an electronic online instrument".

When a quota sample needs to be drawn, the WWW-survey can only be conducted when the product is exclusively sold online (Recommendations 6). Lastly, survey results are submitted (online) only after the data set is complete and all analyses have been made (Recommendation 9).

\subsection{Summary}

In summary it can be stated that the Internet is an advantageous medium for customer satisfaction studies only if specific conditions are met. Companies therefore need to investigate on a case-by-case basis if the online measurement of customer satisfaction is possible in their specific case. A decision-making framework integrating the related recommendations has been introduced.

After the theoretical side of online customer satisfaction measurement has now been investigated, the next section will report on how these investigations are currently conducted in practice.

\section{Online Customer Satisfaction Research in Practice}

In practice, a large amount of approaches to CS measurement are not based on any theoretical foundation at all (Peterson \& Wilson, 1992). The aim of this chapter is to find out if this is also true for the measurement of customer satisfaction on the Internet. Furthermore, possible developments in practice that have not yet been followed or preceded by academic research may be detected. In order to obtain these insights, a survey among marketing research companies offering CS investigations has been undertaken.

\subsection{Methodology}

\subsubsection{Definition of the Population}

For this investigation, the population of interest consists of all marketing research companies and other firms, which are conducting online customer satisfaction surveys. Since it is however impossible to generate a list containing all these entities, two restrictions have been taken into account. Firstly, only marketing research companies and secondly, only marketing research companies in English-speaking countries have been considered. The English-speaking countries of Australia, Canada, the United Kingdom, and the United States of America have been chosen for theoretical as well as practical reasons. These four countries account for more than two thirds of the world's online population. Furthermore, percental access of the respective populations are among the highest in the world, only to be preceded by the Scandinavian countries (NUA, 1998). 


\subsubsection{Data Collection Method and Questionnaire Design}

The survey was conducted via E-mail. This method has been chosen for its cost-advantage and speed of administration. Furthermore, many authors have reported that the majority of answers usually are received within the first three days after the mailing (Comley, 1996; Mehta \& Sivadas, 1995; Oppermann, 1995). Therefore, timely results could be expected. Lastly, the company's access to the medium could be checked easily.

The questionnaire contained questions covering some of the recommendations that have been derived from the literature in the previous section. Because questionnaire length is a critical issue in E-mail surveys, only the most important recommendations have been considered. Since the aim of the survey is to get an indication of how customer satisfaction surveys are conducted in practice and the testing of the framework, this approach should be sufficient to generate the desired results.

In conformance with Esomar's guidelines for Internet research (Esomar, 1999a), the purpose of the survey was clearly stated in the first sentence. Because Batinic and Bosnjak (Batinic \& Bosnjak, 1997a) report that the offer of the survey results increases the response rate in academic research, this was used as an incentive during this survey. Formally, all criteria necessary for an e-mail survey have been met (ASCII format, lines of 65 characters, questions and return address in the body of the mail). A copy of the questionnaire and the reminder letter used can be found in the appendix.

\subsubsection{Identification of a Sampling Frame}

Available sampling frames included the member directories of marketing research associations. In order to qualify as a suitable sampling frame, three conditions had to be fulfilled: The directory had to contain E-mail addresses of its members as well as an indication if the member offers Internet research and/or customer satisfaction research. Furthermore, the directory had to be as current as possible (not older than 1998). The Esomar member directory (Esomar, 1999b) was chosen as the major sampling frame because it contains all members' E-mail addresses and allowed a first segmentation on the type of research wanted (CS research in this case, an indication of online research was not made). Thus, a sampling frame of companies from Australia, Canada and the United Kingdom was obtained. Because the Esomar directory contained few Australian and Canadian companies and no firms from the US, three more sampling frames were used: The Canadian Association of Marketing Research Organizations (CAMRO, 1999), the Market Research Society of Australia (MRSA, 1999) and the Council of American Survey Organizations (CASRO, 1999). While a segmentation of companies on the type of research offered was not possible in all three member directories, homepages or enclosed company information was checked separately. While information content varied widely, companies not specifying the types of investigations they offer were left inside the sampling frame ${ }^{5}$. After double listings were deleted, a sampling frame of 211 members was obtained (40 Australia, 14 Canada, 66 UK, 91 US).

\subsubsection{Selection of a Sampling Procedure and Sampling Elements}

All companies listed in the sampling frame were sent an e-mail survey. As stated in the beginning of this section, the sampling frame chosen does not contain the totality of marketing research companies conducting online research in the countries considered. Furthermore, the selection was not made on a random basis: The sample chosen is a (non-probability) judgement sample in that "the sample elements are hand-picked because it is expected that they can serve the research purpose" (Churchill, 1995, p. 582). The investigation made is therefore an explorative one. The results that are described in the second part of this chapter are therefore by no means representative but only indicate if in general, a gap between theory and practice in Internet CS research exists.

\footnotetext{
${ }^{5}$ The second question in the questionnaire to be sent out therefore asks about the company's offering of online $\mathrm{CS}$ measurements. In the case that this service is not offered, the company is asked to send the questionnaire back without answering the subsequent questions.
} 


\subsubsection{Data Collection}

The survey questionnaire was sent out on Wednesday the28th of April. Before, it was tested for question wording by a native speaker. All questionnaires were sent to the companies' E-mail address for general questions. In cases where only E-mail addresses specific to a contact person (for online/CS research) could be obtained, the E-mail was sent individually and contained a personal salutation. After the first week, a reminder, again containing the questionnaire was sent out to those companies who had not yet responded.

The results of the survey are presented in the following section.

\subsection{Results}

Of the 211 questionnaires that were mailed out, 41 turned out to be undeliverable. In total, 170 questionnaires reached their destination.

The majority of answers to the first mailing occurred within 24 hours. After that, the frequency of responses declined markedly. One week after the first mailing, a response rate of $29.4 \%$ (50 responses) was reached. Subsequently, a reminder, again containing the questionnaire was distributed. Responses again mostly occurred within 24 hours of the mailing. In total, 87 questionnaires were received yielding a response rate of $51.2 \%$. 27 of the respondents (31\%) answered that they do conduct some form of online CS investigations. Of all respondents, approximately $87.4 \%$ (76) indicated that they would like to receive the results of the survey that were offered as an incentive. The topic therefore appears to be of general interest even to companies that are not using online CS research (yet). The current nature of the subject has also been confirmed by various respondents expressing their thanks for the opportunity to participate or apologizing for their late response after the reminder survey.

Figure 5 displays the frequency of responses by the type of online survey used.

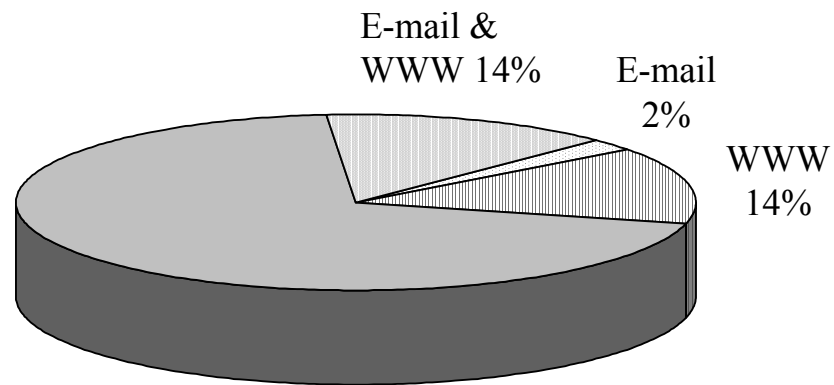

no online surveys $70 \%$

Figure 5: Responses by Type of Survey

$(\mathrm{n}=87)$

\subsubsection{Demographics}

The home countries and numbers of employees of the institutes conducting online customer satisfaction surveys can bee seen in figures 6 and 7. Slightly more than half of these institutes are form the U.S., while only one Canadian company is included in this group. In order to be able to make comparisons between countries, Canada 
and the U.S. (55.6\%, 15 respondents) as well as Australia and the UK (44.4\%, 12respondents) are grouped together. These groups will subsequently be called North-American (15 firms) and Non-North American countries (12 firms), respectively. This grouping has been chosen because the Internet penetration rates of Canada and the U.S. are frequently reported in as figure in Internet statistics. These two counties oftentimes appear to be regarded as one entity concerning Internet statistics.

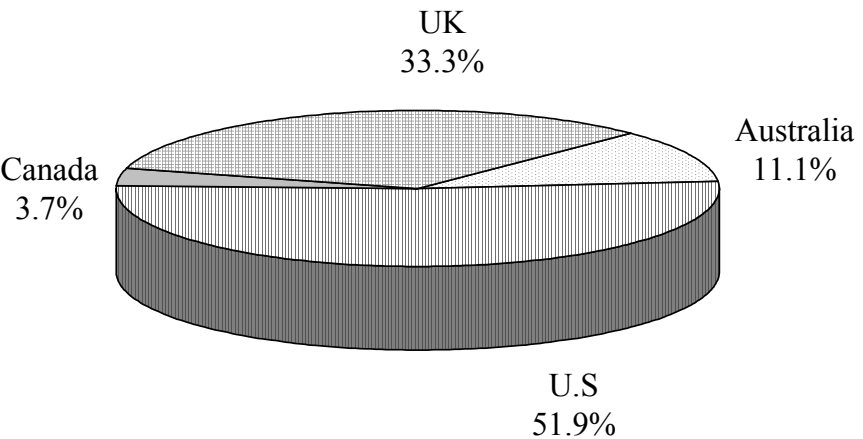

Figure 6: Respondents per Country

$(\mathrm{n}=27)$

In order to see if practices differ between larger and smaller institutes, firms have also been grouped according to the number of their employees. All companies employing less than 100 people are combined into the group of 'small firms' while all institutes with more than 99 employees constitute the group of 'large firms'.

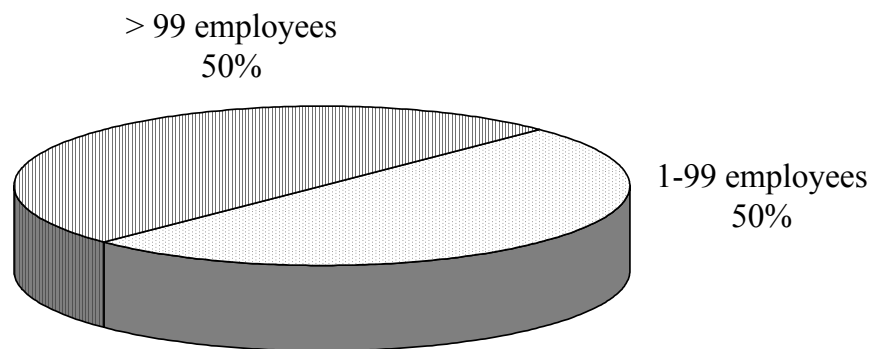

Figure 7: Number of Employees per Company

$(n=26)$

In the remaining parts of this section, the results of the survey will firstly be presented for the totality of firms conducting online CS measurements. Subsequently, differences between countries and firm sizes will be presented. 


\subsubsection{E-mail Surveys}

Of the 27 respondents conducting CS surveys online, 55.5\% do use E-mail surveys. Out of these, 2 respondents use only E-mail surveys while 13 respondents (48.1\%) have indicated that they engage in E-mail as well as WWW-surveys.

Table 2 shows the frequency of answers to the questions related to E-mail surveys.

\begin{tabular}{l|cccc}
\hline Question & "Yes" & "No" & N & $\begin{array}{c}\text { Recommendation } \\
\text { confirmed ? }\end{array}$ \\
\hline $\begin{array}{l}\text { Choice of E-mail depends } \\
\text { on questionnaire length } \\
\text { (R4) }\end{array}$ & $80 \%$ & $20 \%$ & $100 \%$ & Yes \\
\hline Prior customer consent is & $93.3 \%$ & $6.7 \%$ & $100 \%$ & Yes \\
necessary (R2) & $(14)$ & $(1)$ & $(15)$ & \\
\hline
\end{tabular}

Table 2: E-mail Surveys in Practice

As can be seen from the table, the recommendations that have been made in the previous chapter are followed by the majority of the respondents. Several respondents have stated that questionnaire length is not the only factor influencing the choice of E-mail questionnaires. Unfortunately, they did not specify those other factors.

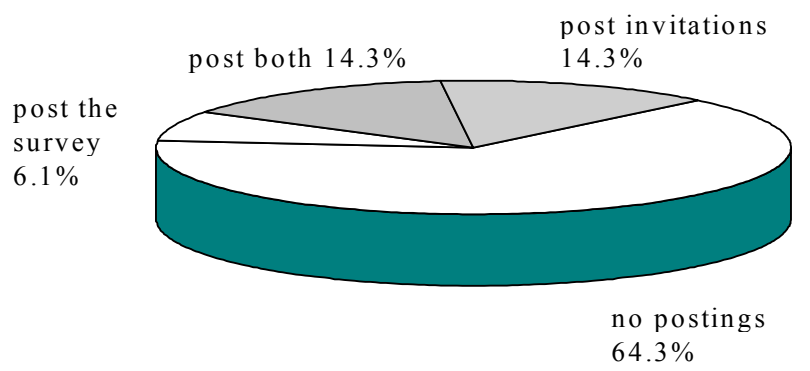

Figure 8: Postings in Newsgroups/on Mailinglists

$(\mathrm{n}=14)$

As can be seen in figure 8, the recommendation of not posting invitations or the survey itself in newsgroups or on mailinglists (chapter 4) is also followed by the majority of respondents. However, in total, $34.7 \%$ do use them. It can be concluded that posting E-mail surveys or invitations to be common in practice to some extent.

\subsubsection{Differences between Countries}

Usage of E-mail surveys is apparently different between countries: $66.7 \%$ of the Non-American firms but only $46.7 \%$ of the North-American companies do use E-mail surveys.

With one exception, the recommendations are also followed when looking at separate country groups. However, only slightly more than half of the American companies (57.1\%) do not post the questionnaire or invitation. In contrast, $75 \%$ of the Non-American firms follow the recommendation of not doing so. It is furthermore 
noteworthy that $37.5 \%$ of the Non-American firms do not believe that the choice of E-mail as the administrative method is dependent on questionnaire length (see table 3).

\begin{tabular}{l|cc|c|cc|c}
\multirow{2}{*}{ Question } & \multicolumn{2}{|c|}{ North-American } & & \multicolumn{2}{c|}{ Non-American } & \\
\cline { 2 - 6 } & "Yes" & "No" & N & "Yes" & "No" & n \\
\hline $\begin{array}{l}\text { Choice of E-mail } \\
\text { depends on } \\
\text { questionnaire length }\end{array}$ & 7 & 0 & 7 & 5 & 3 & 8 \\
$\begin{array}{l}\text { (R4) } \\
(100 \%)\end{array}$ & $(0 \%)$ & $(100 \%)$ & $(62.5 \%)$ & $(37.5 \%)$ & $(100 \%)$ \\
\hline $\begin{array}{l}\text { Prior customer } \\
\text { consent is necessary } \\
\text { (R2) }\end{array}$ & \begin{tabular}{c}
$(100 \%)$ \\
\hline
\end{tabular} & $(0 \%)$ & $(100 \%)$ & $(87.5 \%)$ & $(12.5 \%)$ & $(100 \%)$ \\
\hline
\end{tabular}

Table 3: E-mail Surveys by Country

\subsubsection{Differences between Firm Sizes}

When grouping the respondents according to firms sizes, a rather large overall difference in usage habits can be found: $61.5 \%$ of the large firms use E-mail surveys, but only $46.2 \%$ of the small firms do so. Practices are also different regarding the usage of mailinglists and newsgroups (table 4 ). While $83.3 \%$ of the small companies follow the recommendation $37.5 \%$ of the larger firms do post (contrary to the recommendations).

\begin{tabular}{|c|c|c|c|c|c|c|}
\hline \multirow[b]{2}{*}{ Question } & \multicolumn{2}{|c|}{ Small Firms } & & \multicolumn{2}{|c|}{ Large Firms } & \multirow[b]{2}{*}{$\mathrm{n}$} \\
\hline & "Yes" & "No" & $\mathbf{n}$ & "Yes" & "No" & \\
\hline $\begin{array}{l}\text { Choice of E-mail } \\
\text { depends on } \\
\text { questionnaire length } \\
\text { (R4) }\end{array}$ & $\begin{array}{c}4 \\
(66.7 \%)\end{array}$ & $\begin{array}{c}2 \\
(33.3 \%)\end{array}$ & $\begin{array}{c}6 \\
(100 \%)\end{array}$ & $\begin{array}{c}7 \\
(87.5 \%)\end{array}$ & $\begin{array}{c}1 \\
(12.5 \%)\end{array}$ & $\begin{array}{c}8 \\
(100 \%)\end{array}$ \\
\hline $\begin{array}{l}\text { Prior customer } \\
\text { consent is necessary } \\
(R 2)\end{array}$ & $\begin{array}{c}5 \\
(83.3 \%)\end{array}$ & $\begin{array}{c}1 \\
(16.7 \%)\end{array}$ & $\begin{array}{c}6 \\
(100 \%)\end{array}$ & $\begin{array}{c}8 \\
(100 \%)\end{array}$ & $\begin{array}{c}0 \\
(0 \%)\end{array}$ & $\begin{array}{c}8 \\
(100 \%)\end{array}$ \\
\hline
\end{tabular}

Table 4: E-mail Surveys by Firm Size

Again in line with the recommendations, the majority of respondents feel that customer consent is necessary and that questionnaire length needs to be considered when surveying via E-mail (table 4). The largest disparity in opinions can be found within small firms: $33.3 \%$ do not believe that the choice of E-mail depends on questionnaire length.

\subsubsection{WWW-Surveys}

An almost equal number of respondents indicated that they conduct surveys only on the World Wide Web (12 respondents) or on the WWW as well as via E-mail (13 respondents). These groups together include $92.6 \%$ of all respondents conducting online CS surveys.

In order to obtain representative results when using a sampling frame, it was recommended in the previous chapter that (a) the customers' access to the WWW should be ensured and (b) that the questionnaire should be protected with a password. As can be seen in figure 9 , only $50 \%$ of the participating institutes do assure customer access and at the same time protect the questionnaire with a password. 
assure access to the WWW

$8.3 \%$

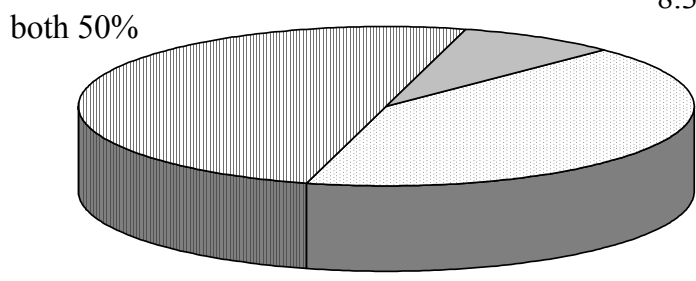

install password-protection

$41.7 \%$
Practices used to ensure participation when a customer quota has to be met vary more widely (Figure 10). Only 50\% of the 22 respondents indicated that they attach the survey to the client's homepage and expose it to the customers randomly, thereby following the recommendations made. Moreover, $68.2 \%$ of the companies use some form

of pre-recruitment. Recruitment practices that were mentioned include e-mail (4 respondents), mail (2 respondents) or telephone invitations ( 5 respondents) and recruitment form a panel (4 respondents). It is also noteworthy that approximately one third of all firms advertise the survey although this leads to the respondents' self-selection and biased results, among other things.

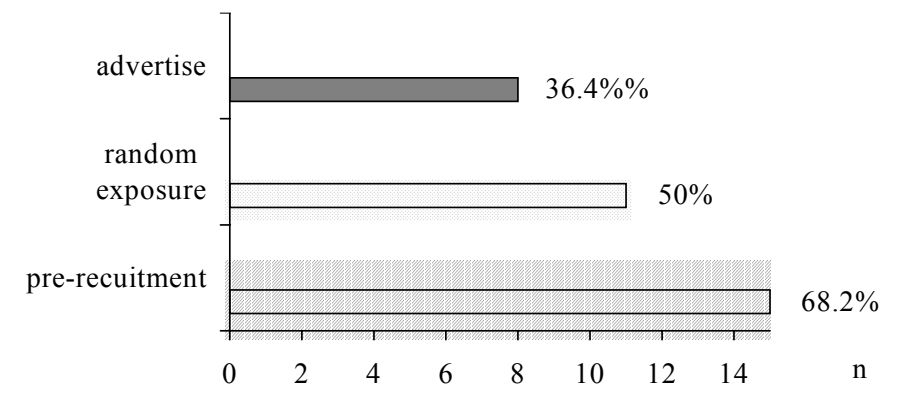

$\mathrm{n}=22$ )

Figure 10: $W W W$ Surveys: Quota Sampling (R6)

In table 5, the answers to the remaining questions concerning WWW-surveys are presented.

\begin{tabular}{l|cccc}
\hline Question & "Yes" & "No" & N & $\begin{array}{c}\text { R confirmed } \\
\text { ? }\end{array}$ \\
\hline $\begin{array}{l}\text { Submission of results } \\
\text { after each returned } \\
\text { questionnaire (R9) }\end{array}$ & $24 \%$ & $76 \%$ & $100 \%$ & Yes \\
\hline Combination of & $40 \%$ & $60 \%$ & $100 \%$ & Unclear \\
$\begin{array}{l}\text { WWW- and } \\
\text { E-mail Surveys (R11) }\end{array}$ & $(10)$ & $(15)$ & $(25)$ & \\
\hline $\begin{array}{l}\text { Postings of } \\
\text { invitations in }\end{array}$ & $20.8 \%$ & $79.2 \%$ & $100 \%$ & Yes \\
newsgroups / on & $(5)$ & $(19)$ & $(24)$ & \\
mailinglists & & & & \\
\hline
\end{tabular}

Table 5: WWW-Surveys in Practice 
The recommendations relating to the first and last questions of this table are again followed by the majority of the companies. Concerning the combination of WWW- and E-mail surveys, practices are more divided. More than half of the institutes do not use combinations while $40 \%$ combine surveys. However, the results of this question might not be accurate. While several respondents have stated that they use E-mail to invite customers to the survey, this in fact does not constitute a combination of methods for data collection ${ }^{6}$. It can therefore be suspected that more of the firms having stated that they do use combinations do not do so for the actual data collection.

\subsubsection{Differences between Countries}

All of the respondents from North-America and $83.4 \%$ of the Non-American institutes do conduct WWWsurveys.

When using a sampling frame, less than half of the American firms (40\%) but $66.7 \%$ of the Non-American firms protect the questionnaire with a password and assure their customers' access to the WWW at the same time (as recommended). Companies should be aware that although Internet penetration rates are among the highest in North America, even there a mass penetration is still far from realized.

When meeting a customer quota, North-American firms prefer some form of pre-recruitment (73.3\%), followed by the random exposure of the questionnaire (40\%). In contrast, Non-American firms mainly expose the questionnaire randomly $(71.4 \%)$ and pre-recruit their respondents less frequently $(57.1 \%)$. However, contrary to the recommendations, $57.1 \%$ of the Non-American but only $26.7 \%$ of the American firms advertise their survey.

\begin{tabular}{|c|c|c|c|c|c|c|}
\hline \multirow[b]{2}{*}{ Question } & \multicolumn{2}{|c|}{ North-American } & \multirow[b]{2}{*}{$\mathbf{n}$} & \multicolumn{2}{|c|}{ Non-American } & \multirow[b]{2}{*}{$\mathbf{n}$} \\
\hline & "Yes" & "No" & & "Yes" & "No" & \\
\hline $\begin{array}{l}\text { Submission of results } \\
\text { after each returned } \\
\text { questionnaire (R9) }\end{array}$ & $\begin{array}{c}3 \\
(20 \%)\end{array}$ & $\begin{array}{c}12 \\
(80 \%)\end{array}$ & $\begin{array}{c}15 \\
(100 \%)\end{array}$ & $\begin{array}{c}3 \\
(30 \%)\end{array}$ & $\begin{array}{c}7 \\
(70 \%)\end{array}$ & $\begin{array}{c}10 \\
(100 \%)\end{array}$ \\
\hline $\begin{array}{l}\text { Combination of } \\
W W W \text { - and E-mail } \\
\text { Surveys (R11) }\end{array}$ & $\begin{array}{c}8 \\
(53.3 \%)\end{array}$ & $\begin{array}{c}7 \\
(46.7 \%)\end{array}$ & $\begin{array}{c}15 \\
(100 \%)\end{array}$ & $\begin{array}{c}2 \\
(20 \%)\end{array}$ & $\begin{array}{c}8 \\
(80 \%)\end{array}$ & $\begin{array}{c}10 \\
(100 \%)\end{array}$ \\
\hline $\begin{array}{l}\text { Postings of } \\
\text { invitations in } \\
\text { newsgroups / on } \\
\text { mailinglists }\end{array}$ & $\begin{array}{c}4 \\
(26.7 \%)\end{array}$ & $\begin{array}{c}11 \\
(73.3 \%)\end{array}$ & $\begin{array}{c}15 \\
(100 \%)\end{array}$ & $\begin{array}{c}1 \\
(11.1 \%)\end{array}$ & $\begin{array}{c}8 \\
(88.9 \%)\end{array}$ & $\begin{array}{c}9 \\
(100 \%)\end{array}$ \\
\hline
\end{tabular}

Table 6: $W W W$ - Surveys by Size of Institute

Concerning the questions in table 6, the majority of respondents follows the recommendations. One exception, however, is again the combination of WWW-and E-mail surveys. Practices of North-American companies are almost divided equally: $53.3 \%$ do combine them and $46.7 \%$ do not. However, the same caution that applied before should be kept when interpreting the results of this question.

\subsubsection{Differences between Firm Sizes}

In total, all of the large firms and $84.6 \%$ of the small companies use WWW-surveys.

\footnotetext{
${ }^{6}$ Those respondents' answers have been classified as a "no" to this question.
} 
When using a sampling frame, only $38.5 \%$ of the large firms do assure customer access and protect the questionnaire with a password at the same time. In contrast, $60 \%$ of the small firms follow the recommendations and do both.

When meeting a customer quota on the WWW, some form of pre-recruitment is used most often within both groups (small firms: 77.8\%; large firms: 61.5\%), again followed by the random exposure of the questionnaire (small firms: 44.4\%; large firms: 53.8\%). Advertising is still popular with $33.3 \%$ of the small firms and $38.5 \%$ of the large companies.

\begin{tabular}{|c|c|c|c|c|c|c|}
\hline \multirow[b]{2}{*}{ Question } & \multicolumn{2}{|c|}{ Small Firms } & \multirow[b]{2}{*}{ 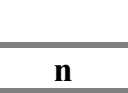 } & \multicolumn{2}{|c|}{ Large Firms } & \multirow[b]{2}{*}{$\mathbf{n}$} \\
\hline & "Yes" & "No" & & "Yes" & "No" & \\
\hline $\begin{array}{l}\text { Submission of results } \\
\text { after each returned } \\
\text { questionnaire }(R 9)\end{array}$ & $\begin{array}{c}2 \\
(18.2 \%)\end{array}$ & $\begin{array}{c}9 \\
(81.8 \%)\end{array}$ & $\begin{array}{c}11 \\
(100 \%)\end{array}$ & $\begin{array}{c}4 \\
(30.8 \%)\end{array}$ & $\begin{array}{c}9 \\
(69.2 \%)\end{array}$ & $\begin{array}{c}13 \\
(100 \%)\end{array}$ \\
\hline $\begin{array}{l}\text { Combination of } W W W- \\
\text { and E-mail Surveys }(R \\
11)\end{array}$ & $\begin{array}{c}3 \\
(27.3 \%)\end{array}$ & $\begin{array}{c}8 \\
(72.7 \%)\end{array}$ & $\begin{array}{c}11 \\
(100 \%)\end{array}$ & $\begin{array}{c}7 \\
(53.8 \%)\end{array}$ & $\begin{array}{c}6 \\
(46.1 \%)\end{array}$ & $\begin{array}{c}13 \\
(100 \%)\end{array}$ \\
\hline $\begin{array}{l}\text { Postings of invitations } \\
\text { in newsgroups / on } \\
\text { mailinglists }\end{array}$ & $\begin{array}{c}1 \\
(9 \%)\end{array}$ & $\begin{array}{c}10 \\
(90.9 \%)\end{array}$ & $\begin{array}{c}11 \\
(100 \%)\end{array}$ & $\begin{array}{c}4 \\
(30.8)\end{array}$ & $\begin{array}{c}9 \\
(69.2 \%)\end{array}$ & $\begin{array}{c}13 \\
(100 \%)\end{array}$ \\
\hline
\end{tabular}

Table 7: WWW-Surveys by Firm Size

As can be seen in table 7, all other recommendations concerning WWW-surveys are followed by the majority of small and large firms. However, no consistent practice concerning the combination of WWW- and E-mail surveys in the same investigation exists within the group of large firms. Again, caution should be used when interpreting the results of this question.

\subsection{Summary}

Within this chapter, an investigation of how online customer satisfaction surveys are conducted in practice was presented. Overall, in agreement with the recommendations of this paper, WWW surveys appear to be more popular than E-mail survey.

Furthermore, the majority of respondents conduct E-mail surveys according to the recommendations put forward earlier.

However, the situation is different when looking at the companies' practices of surveying on the World Wide Web. Contrary to the recommendations, only half of the respondents assure the customers' access to the WWW and at the same time protect the questionnaire with a password when a sampling frame is used. Also contrary to the recommendations $40 \%$ combine Email and WWW-surveys. However, some respondents stated that they use E-mail only to invite customers to the survey.

In the case that a customer quota has to be met, the majority of respondents uses some form of pre-recruitment. Practices mentioned include E-mail and telephone invitation and panel recruitment. Again in line with the recommendations, most institutes do not submit the results after each incoming questionnaire and do not post invitations in newsgroups or on mailinglists.

While some differences in practices were found between large and small firms and American and Non-American companies, the most striking finding is that more than half of large firms and American companies do combine E-mail and WWW-surveys. However, the results again need to be treated cautiously. Furthermore, the majority of American firms and large firms do not assure that their customers have access to the WWW and passwordprotect the questionnaire at the same time. 


\section{Conclusion}

This paper investigated the problem of how customer satisfaction measurements can be conducted on the Internet. Because of the difference in the satisfaction formation between products and services, customer satisfaction with products has been the focus of the discussion.

Concluding, customer satisfaction measurements on the Internet was identified as an interesting new opportunity. Especially World Wide Web surveys offer the researcher opportunities that are not available with any other administrative method. Pervasive advantages of WWW- and E-mail surveys include administrative and response speed, cost savings, and global reach of respondents. However, while the Internet is still far from being a mass medium, self-selection of the respondents and the target populations' access to the medium are the most immediate problems to deal with. It was shown that representative and reliable results can only be obtained when very specific conditions are met. Researchers need to investigate step-by-step if the online measurement of customer satisfaction is possible in their specific situation. A decision making framework is proposed to aid CS researchers in choosing the correct data collection method.

A survey among practitioners showed that a large number of them is aware of the factors that need to be considered when measuring customer satisfaction on the Internet. However, some practices that cannot be recommended from a theoretical viewpoint are being used to some extent. These results are a first indication of how customer satisfaction surveys are conducted in practice. Since the results are based on a non-representative convenience sample, these results are not representative for the larger population of firms conducting customer satisfaction surveys online. Based on these first insights and emerging results of Internet research, further studies should be undertaken to refine the proposed framework and to evaluate future practices.

Within this paper, the current state of knowledge about Internet-based research was accumulated and applied to the measurement of customer satisfaction. However, due to the novelty of the medium, a lot of developments are still to happen and many more research results are certain to come. While a mass penetration of the medium is the most desirable state for marketing researchers, it is questionable if this will be reached within the near future. 


\section{Appendix}

\subsection{The survey}

Dear,

This academic survey investigates how customer satisfaction surveys on the Internet

are conducted in practice. It is part of my masters thesis at the University of Maastricht

in The Netherlands. Your company address has been obtained from The answering of these questions will not take you longer than five minutes.

As a token of my appreciation for your very valuable contribution I can offer you the results

of this survey. Please indicate below if you wish to receive them. I assure you that your

answers will be treated confidentially and will by no means made accessible to third parties.

Should you have any questions, please do not hesitate to contact me via email: Katja88@gmx. net

Sincerely

Katja Hofmaier

I. Would you like to receive the results of this survey?

( ) No

( ) Yes, your e-mail:

1. Do you conduct customer satisfaction surveys via E-mail and/or on the World Wide Web?

(multiple answers possible)

( ) E-mail, continue with question 2

( ) World Wide Web, continue with question 5

( ) none of the above, do not answer the following questions, just send the questionnaire back via reply

E-mail Surveys

2. Do you ask for the customers' consent before sending out E-mail questionnaires?

( ) Yes ( ) No 
3. Do you believe that the choice of E-mail as the administrative method is dependent on the length of the questionnaire?

( ) Yes ( ) No

4. Do you make postings on newsgroups or in mailinglists to increase the awareness to the survey? (multiple answers possible)

( ) you post invitations

( ) you post the survey itself

( ) none of the above

WWW-Surveys

5. If you have a sampling frame available, you (multiple answers possible)

( ) assure customers' access to the WWW before posting the questionnaire

( ) protect the questionnaire with a password

6. If you have to meet a customer quota, you (multiple answers possible)

( ) place the survey on the WWW and advertise it

( ) attach the survey to your client's homepage and expose it to the visitors randomly

( ) other:

7. Do you submit the results of the survey online to your client after each returned

questionnaire?

( ) Yes ( ) No

please motivate:

8. Do you combine E-mail and WWW-surveys in the same survey?

( ) Yes ( ) No

please motivate:

9. Do you post invitations on newsgroups or in mailinglists to increase the awareness

to the survey?

( ) Yes ( ) No

Exploratory Phase

10. Do you conduct online focus groups in the exploratory phase?

( ) Yes ( ) No 
11. Do you combine online focus groups with in-person focus groups in the same survey?

( ) Yes ( ) No

please motivate:

12. How do you interview client personnel during the exploratory phase? (multiple answers possible)

( ) in-person

( ) online, via

13. Do you believe that Virtual Communities will be useful for customer satisfaction surveys

in the future?

( ) Yes ( ) No ( ) Undecided

please motivate:

Your company

14. How many people work in your company?

people

15. In which country is your company located?

Thank you very much for your valuable time and cooperation! 


\section{References}

Aaker, D. A., Kumar, V., \& Day, G. S. (1998). Marketing Research. (6 ed.). New York: Wiley.

Agrawal, D. (1998). Market Research. In S. Albers, C. M., \& K. Peters (Eds.), Marketing mit Interaktiven Medien (pp. 193-206). Frankfurt: Institut für Medienentwicklung und Kommunikation GmbH.

Anderson, S., \& Gansneder, B. (1995). Using electronic mail surveys and computer-monitored data for studying computer-mediated communication systems. Social Science Computer Review, 13(1), 33-46.

Bachmann, D., Elfrink, J., \& Vazzana, G. (1996). Tracking the progress of e-mail vs. snail-mail. Marketing Research, 8(2), 30-35.

Bandilla, W. (1997). Überlegungen zu Selektionseffekten bei unterschiedlichen Formen der computergestützten Datenerhebung. GOR 1997 Abstract. Available: http://infosoc.uni-koeln.de/girlws/abstracts/fr_02.html [1999, March 30].

Bandilla, W., \& Hauptmanns, P. (1998). Internetbasierte Umfragen als Datenerhebungstechnik für die empirische Sozialforschung. ZUMA-Nachrichten, 45(22), 36-53.

Batinic, B. (1997). Die Durchführung von Fragebogenuntersuchungen im Internet - Ein erster Überblick. Available: http://www.psychol.uni-giessen.de/XBatinic/survey/faq3.htm [1999, January 10].

Batinic, B., \& Bosnjak, M. (1997a). Determinanten der Teilnahmebereitschaft an Internet-basierten Fragebogenuntersuchungen. GOR 1997 [1999, March 8].

Batinic, B., \& Bosnjak, M. (1997b). Fragebogenuntersuchungen im Internet. In B. Batinic (Ed.), Internet für Psychologen . Göttingen: Hogrefe-Verlag.

Berger, K., \& Mens van, M. (1997). Klantevredenheid \& Loyaliteit. Alphen: Adfo DM \& SP Dossier.

Bogner, W. (1996). Die Validität von Online-Befragungen. Planung und Analyse, 6, 9-12.

Booker, E. (1996). E-Mail tool lets webmasters conduct targeted surveys. Web Week, 14(2).

Bosnjak, M., \& Batinic, B., , [Online], Available: , [1999, March 08]. (1997). Zur Äquivalenz von WWW-und EMail Umfragen: Ergebnisse zur Reliabilität und 'Sozialen Erwünschtheit'. GOR 97 Abstract. Available: http://solix.wiso.uni-koeln.de/girlws/abstracts/fr_10.html [1999, March 8].

Boulding, W., Kalra, A., Staelin, R., \& Zeithaml, V. A. (1993). A dynamic process model of service quality: From expectations to behavioral intentions. Journal of Marketing Research, 30(February), 7-27.

Breitner, A., \& Batinic, B. (1997). Das Internet als Basis für elektronische Befragungen. Jahrbuch der Verbrauchs- und Absatzforschung(2), 214-229.

Briggs, R. O., Nunamaker, J., \& Sprague, R. (1998). 1001 Unanswered Questions in GSS. Journal of Management Information Systems, 14(3).

Bruhn, M. (1997). Qualitätsmanagement für Dienstleistungen; Grundlagen, Konzepte, Methoden. (2 ed.). Berlin: Springer Verlag.

Bruhn, M. (1998). Nationale Kundenbarometer als Ansatzpunkte zur Verbesserung der Kundenorientierung Konzept und empirische Ergebnisse des Schweizer Kundenbarometer. Die Unternehmung: Schweizerische Zeitschrift für betriebswirtschaftliche Forschung und Praxis, 52(5/6), 271-295.

Buchanan, T., \& Smith, J. L. (1999). Using the Internet for Psychological Research: Personality Testing on the World Wide Web. British Journal of Psychology, 90, 125-144.

CAMRO. (1999). CAMRO Members. Available: http:www.amro.org/CM.htm [1999, April 15].

Carl, C. (1998). Soziale Gebrauchsweisen des Internes. Eine Techniksoziologische Untersuchung auf Empirischer Basis. Unpublished Master's thesis, University of Hamburg, Hamburg.

Carver, S., Kingston, R., \& Turton, I. (1998). Review of Graphical Environments on the WWW as a Means of Widening Public Participation in Social Science Research. School of Geography, University of Leeds. Available: http://www.agocg.ac.uk/sosci/casestudies/carver/review.html [1999, February 27].

CASRO. (1999). Membership List. Available: http:www.casro.org.member1.htm \& http:www.casro.org.member2.htm \& http:www.casro.org.member3.htm [1999, April 13]. 
CAUBE. . Latest News: Information for Businesses. Available: http:www.caube.org.au/business.htm [1999, February 25].

Churchill, G. A. (1995). Marketing Research: Methodological Foundations. (6 ed.). Fort Worth: The Dryden Press.

Comley, P. (1996). The Use of the Internet as a Data Collection Method. Available: http://www.sga.co.uk/esomar.html [1999, January 23].

Coomber, R. (1997). Using the Internet for Survey Research. Sociological Research Online, 2(2).

Cooper, D. R., \& Emory, W. E. (1995). Business Research Methods. (5 ed.). Chicago: Irwin.

CustomerSat.com. (1999a). Using the Internet to Measure and Increase Customer Satisfaction \& Loyalty. Available: www.customersat.com/uni/whiteindex.html [1999, January 2].

CustomerSat.com. (1999b, January). Web-based Tracking Studies. Available: http://www.customersat.com/services/wbsgindex.html [1999, February 28].

CyberDialogue. (1998). E-Groups. Available: http://www.cyberdialogue.com/products/custom/focus_group.html [1999, January 23].

De Ruyter, K., Bloemer, J., \& Peeters, P. (1997). Merging Service Quality and Service Satisfaction: An Empirical Test of an Integrative Model. Journal of Economic Psychology, 18, 387-706.

Dennis, A. R., Valacich, J. S., Connolly, T., \& Wynne, B. E. (1996). Process Structuring in Electronic Brainstorming. Information Systems Research, 7(2), 268-277.

Dutka, A. F. (1994). AMA Handbook for Customer Satisfaction. Lincolnwood: NTC Business Books.

Engel, J. F., Blackwell, R. D., \& Miniard, P. W. (1995). Consumer Behavior. (8 ed.). Fort Worth: The Dryden Press.

Esomar. (1999a, January 11). Conducting Marketing and Opinion Research Using the Internet. Available: http://www.esomar.nl/guidelines/internet_guidelines.htm [1999, February 12].

Esomar. (1999b). Member Directory 1998. Available: http://www.esomar.nl/directory.html [1999, April 13].

EuroCauce. (1999). The European Coalition against Unsolicited Commercial Email: The Situation. Available: http://www.euro.cauce.org\#situation [1999, MArch 16].

Eversheim, W. (1997). Qualitätsmanagement für Dienstleister: Grundlagen, Selbstanalyse, Umsetzungshilfen. Berlin: Springer Verlag.

Fowler, B. (1997). Pierre Bourdieu and cultural theory : critical investigations. London: Sage.

Gadeib, A. (1999). Ansprüche und Entwicklung eines Systems zur Befragung über das World Wide Web. In B. Batinic, L. Gräf, A. Werner, \& W. Bandilla (Eds.), Online Research - Methoden, Anwendungen und Ergebnisse (pp. 103-111). Göttingen: Hogrefe.

Götte, A., \& Kümmerlein, K. (1996). Der Einsatz von Multimedia in der Marktforschung. Planung und Analyse, $6,36-41$.

Gräf, L. (1998, January 30). Auswertung von E-Mail Befragungen, Archiv Mailinglist German Internet Research List gir-l. Available: http://infosoc.uni-koeln.de/archives/gir-1/msg00536.html [1999, March 11].

Grüne, H. (1998). Online und Online-Forschung in Deutschland - eine schwierige Kombi-Nation? Planung und Analyse, 1, 10-13.

Gupta, K., \& Stewart, D. W. (1996). Customer Satisfaction and Customer Behavior: The Differential Role of Brand and Category Expectations. Marketing Letters, 7(3), 249-263.

Hagel III, J. H., \& Armstrong, A. G. (1997). Net Gain -Profit im Netz: Märkter erobern mit Virtuellen Communities. Wiesbaden: Gabler.

Hagel III, J. H., \& Sacconaghi Jr., A. M. (1996). Who will benefit from Virtual Information? The McKinsey Quarterly, 3, 23-37.

Hagenhoff, W., \& Pfleiderer, R. (1998). Neue Methoden der Online Forschung. Planung und Analyse, 1, 26-30.

Halstead, D., Hartmann, D., \& Schmidt, S. L. (1994). Multisource Effects on the Satisfaction Process. Journal of the Academy of Marketing Science, 22(2), 114-129. 
Hambridge, S. (1995). RFC 1855 Netiquette Guidelines. Available: http://Markting.tenagra.com/rfc1855.html [1999, February 02].

Hanan, M., \& Karp, P. (1989). Customer satisfaction. New York: Amacom.

Hauptmanns, P. (1997). Empirische Forschung Online - Grenzen und Chancen von Quantitativen Befragungen mit Hilfe des Internets. GOR 97. Available: http://solix.wiso.uni-koeln.de/girlws/abstracts/fr_03.html [1999, March 08].

Hayes, B. E. (1992). Measuring Customer Satisfaction: Development and Use of Questionnaires. Milwaukee: ASQC Quality Press.

Homburg, C., \& Rudolph, B. (1995). Wie zufrieden sind Ihre Kunden tatsächlich? Harvard Business Manager, $1,43-50$.

Homburg, C., \& Werner, H. (1996). Ein Meßsystem für die Kundenzufriedenheit. Absatzwirtschaft, 11, 92-100.

Johnson, M. D., Anderson, E. W., \& Fornell, C. (1995). Rational and Adaptive Perfor-mance Expectations in a Customer Satisfaction Framework. Journal of Consumer Research, 21(March), 695-707.

Kaapke, A., \& Hudet, K. (1998). Der Einsatz des Kano-Modells zur Ermittlung von Indikatoren der Kundenzufriedenheit. Jahrbuch der Verbrauchs- und Absatzforschung, 3, 267-287.

Kannan, P. K., Chang, A., \& Whinston, A. (1998). Marketing Information on the I-Way. Communications of the $A C M, 41(3), 35-43$.

Kehoe, C. M., \& Pitkow, J. E. (1997, 3). Surveying the Territory: GVU's Five WWW User Surveys. WWW Journal. Available: http://www.w3j.com/3/s3.kehoe.html [1999, January 23].

Kiesler, S., \& Sproull, L. (1992). Group Decision Making and Communication Technology. Organizational Behavior and Human Decision Making Processes, 52, 96-123.

Kiesler, S., \& Sproull, L. S. (1986). Response Effects in the Electronic Survey. Public Oppinion Quarterly, 50, 402-413.

King Jr., W. C., \& Miles, E. W. (1995). A Quasi-Experimental Assessment of the Effect of Computerizing Noncognitive Paper-and Pencil Measurements: A Test of Measurement Equivalence. Journal of Applied Psychology, 80(6), 643-651.

Kittleson, M. J. (1995). An assessment of the response rate via the postal service and e-mail. Health Values, $18(2), 27-29$.

Klingebiel, N. (1998). Erhebungs- und Bewertungscontrolling der Kundenzufriedenheit. Jahrbuch der Verbrauchs- und Absatzforschung(3), 307-334.

Kotler, P. (1994). Marketing Management. (8 ed.). Englewood Cliffs: Prentice Hall International.

Krasilovsky, P. (1996). Surveys in Cyberspace. American Demographics, Tools Supplement(Nov-Dec), 18-22.

Kurzman, C. (1998, May 15). What's the Fine Line between LegitimateE-mail Marketing and, well ... Spam? Available: http://www.searchz.com/clickz/051598.shtml [1999, February 11].

Lander, B. (1998). Güte von Internet Umfragen. GOR 98. Available: http://infosoc.unikoeln.de/gor98/abstracts/showabst.htm/a15 lander [1999, March 18].

Levy, P. (1998, January). Productive Chat: Can a Chat Room help Marketing Plans? Internet World magazine. Available: http://www.nfor.com/nforesearch/nfoi_talkcity.asp [1999, March 08].

Lingenfelder, M., \& Schneider, W. (1992). Die Kundenzufriedenheit. Marketing ZFP, 2, 109-119.

Mehta, R., \& Sivadas, E. (1995). Comparing Response Rates and Response Content in Mail versus Electronic Mail Surveys. Journal of the Market Research Society, 37(4), 429-439.

MRSA. (1999, February). Market Research Society of Australia: Directory of Suppliers. Available: http:www.mrsa.com.au/direct2.htm [1999, April 15].

Müller, W. (1998). Gerechtigkeitstheoretische Grundlagen der Kundenzufriedenheit. Jahrbuch der Absatz- und Verbrauchsforschung(3), 239-265.

Naether, W. (1995). Marktforschung im Cyberspace: Goldene Zeiten für Marktforscher? Absatzwirtschaft(12), 62-66. 
Naether, W. (1996). Marktforschung im Cyberspace: Chancen und Grenzen. Planung und Analyse(2), 28-33.

NFO. . A Comparison of Qualitative Focus Group Research Formats: Traditional In-Person vs. New Media

Online. NFO Worldwide Inc. Available: http://www.nforesearch/nfoi_netfocuswhitepaper.asp [1999, March 08].

NFO. . NFO://net.focus. NFO Worldwide Inc. Available: http://www.nfor.com/nforesearch/nfoi_netfocus.asp [1999, March 08].

NUA. (1998). Network Wizard's Internet Domain Survey; A Global Perspective. Available: http://www.nua.ie/surveys/analysis/domain_survey_analysis.html [1999, September 8].

Oliver, R. L. (1993a). Cognitive, Affective, and Attribute Bases of the Satisfaction Process. Journal of Consumer Research, 20(December), 418-430.

Oliver, R. L. (1993b). A Conceptual Model of Service Quality and Service Satisfaction: Compatible Goals, Different Concepts. Advances in Services Marketing and Management, 1(2), 65-85.

Oliver, R. L., \& De Sarbo, W. S. (1988). Response Determinants in Customer Satisfaction Judgements. Journal of Consumer Research, 14, 495-507.

Oliver, R. L., Rust, R., \& Varki, S. (1997). Customer Delight: Foundations, Findings, and Managerial Insight. Journal of Retailing, 73(3), 311-336.

Oppermann, M. (1995). E-mail Surveys - Potentials and Pitfalls. Marketing Research, 7(3), 29-33.

Parker, L. (1992). Collecting data the e-mail way. Training and Development(July), 52-54.

Patterson, P. G., Johnson, L. W., \& Spreng, R. A. (1997). Modelling the determinants of customer satisfaction for business-to-business professional services. Journal of the Academy of Marketing Science, 25(1), 417.

Paul, C., \& Runte, M. (1998). Virtuelle Communities. In S. Albers, M. Clement, \& K. Peters (Eds.), Marketing mit Interaktiven Medien . Frankfurt/Main: Institur für Medienentwicklung und Kommunikation GmbH.

Peter, J. P., \& Olson, J. C. (1996). Consumer Behavior and Marketing Strategy. (4 ed.). Chicago: Irwin.

Peterson, R. A., \& Wilson, W. R. (1992). Measuring customer satisfaction: Fact and artifact. Journal of the Academy of Marketing Science, 20(1), 61-71.

Pfleiderer, R. (1997). Repräsentative Daten für Websites: Der n-te Besucher. German Online Research Tagung (GOR 97) Abstract. Available: http://solix.wiso.uni-koeln.de/girlws/abstarcts/fr_05.html [1999, March 8].

Ramos, M. E. (1996). Key Measurement Programs for a Customer Satisfaction System in a Business-toBusiness Market, . Available: http://www.quirks.com/CGIIN/SM40i.exe?docid=3000:58911\&\%70assArticleId=7 [1999, February 11].

Ronig, M. (1998). Marktforschung im Internet: Die Methodik von Befragungen. Unpublished Master's thesis, Rheinisch-Westfälische Technische Hochschule (RWTH), Aachen.

Rosenfeld, P., Booth-Kewley, S., \& Edwards, J. E. (1993). Computer-administered surveys in organizational settings: alternatives, advantages, and applications. American Behavioral Scientist, 36(4), 485-511.

Sassenberg, K. (1999). Sozialer Einfluß unter Anonymität. Georg-Elias-Müller-Institut für Psychologie Göttingen. Available: http://www.gwdge.de/Xpsyweb/wirt_kom/fr_wirt_forsch1.html [1999, March 24].

Sassenberg, K., \& Kreutz, S. (1997). Online Research und Anonymität. Experimente im WWW und mit Internet Relay Chats. GOR 97 Abstract. Available: http://solix.wiso.uni-koeln.de7Girlws/abstarcts7fr_07.html [1999, March 3].

Schillewaert, N., Langerak, F., \& Duhamle, T. (1998). Non-probability sampling for WWW surveys: A comparison of methods. Journal of the Market Research Society, 40(4), 307-322.

Schonland, A., \& Williams, P. (1996). Using the Internet for travel and tourism survey research: Experiences from the Net Traveler Survey. Journal of Travel Research, 35(2), 81-87.

Schuldt, B., \& Totten, J. (1994). Electronic mail vs. mail survey response rates. Marketing Research, 6, 36-39. 
Selwyn, N., \& Robson, K. (1998). Using E-mail as a research tool. Social Research Update, 21.

Slevin, J., \& Chisholm, J. (1997). CustomerSat.com: Billion technology firm conducts worldwide customer satisfaction survey via the Internet. Marketing Research Review(October).

Smith, C. B. (1997). Casting the net: Surveying an Internet population. Journal of Computer Mediated Communication, 3(1).

Solomon, M. B. (1998, July 17). Marketing Research In Cyberspace. Available: http://www.cyberdialogue.com/press/articles/marketingcybersoace.html [1999, January 23].

Spreng, R. A., McKenzie, S. B., \& Olshavsky, R. W. (1996). A reexaminantion of the determinants of consumer satisfaction. Journal of Marketing, 60(July), 15-32.

Stauss, B., in: (edts): , 2nd edition, , pp. (1995). "Augenblicke der Wahrheit" in der Dienstleistungserstellung. Ihre Relevanz und ihre Messung mit Hilfe der Kontaktpunktanalyse. In M. Bruhn \& B. Stauss (Eds.), Dienstleistungsqualität, Konzepte, Methoden, Erfahrung (2 ed., pp. 379-399). Wiesbaden.

Töpfer, A. (1996). Anforderungen und Probleme bei der Messung von Kundenzufriedenheit. In A. Ahsen von \& T. Czenskowski (Eds.), Marketing und Markt-forschung: Entwicklungen, Erweiterungen und Schnittstellen (pp. 499-513). Hamburg: LIT Verlag.

Tse, A. C. B. (1998). Comparing the response rate, response speed and response quality of two methods of sending questionnaires: E-mail vs mail. Journal of Market Research Society, 40(4), 353-362.

Tse, A. C. B., Tse, K. C., Yin, C. H., Ting, C. B., Yi, K. W., Yee, K. P., \& Hong, W. C. (1995). Comparing two methods of sending out questionnaires: E-mail versus mail. Journal of the Market Research Society, 37(4), 441-446.

Tse, D. K., \& Wilton, P. C. (1988). Models of consumer satisfaction formation: An extension. Journal of Marketing Research, 25(2), 204-212.

Tuten, T. L. (1997). Electronic Methods of Collecting Survey Data: A Review of E-Research. ZUMAArbeitsbericht 97/09. Available: http://www.zuma-mannheim.de/publications/series /workingpapers/97_09abs.htm [1999, September 8].

Werner, A. (1997a). The problem of self-selection - Some solutions. In W. Bandilla \& F. Faulbaum (Eds.), SoftStat '97: Advances in Statistical Software 6 (pp. 167-172). Stuttgart: Lucius \& Lucius.

Werner, H. (1997b). Messung und Management von Kundenzufriedenheit. Werbeforschung \& Praxis(3), 8-11.

Werner, U. (1998). On-line Recht: Marktforschung und Datenerhebung. Available: http://www.ulrichwerner.com/online-recht/t6.html [1999, March 16].

Whatt, J. H. (1997). Using the Internet for Quantitative Survey Research. Available: http://www.SwiftInteractive.com/white-p1.htm [1999, January 27].

Zacharias, R. (1998). Was ist dem Kunden wichtig? Absatzwirtschaft, 8, 102-105. 